\title{
A comprehensive numerical study of aerosol-cloud-precipitation interactions in marine stratocumulus
}

\author{
Y.-C. Chen ${ }^{1}$, L. Xue ${ }^{2}$, Z. J. Lebo ${ }^{1}$, H. Wang ${ }^{3}$, R. M. Rasmussen ${ }^{2}$, and J. H. Seinfeld ${ }^{1,4}$ \\ ${ }^{1}$ Division of Engineering and Applied Science, California Institute of Technology, Pasadena, California, USA \\ ${ }^{2}$ National Center for Atmospheric Research (NCAR), Boulder, Colorado, USA \\ ${ }^{3}$ Pacific Northwest National Laboratory (PNNL), Richland, Washington, USA \\ ${ }^{4}$ Division of Chemistry and Chemical Engineering, California Institute of Technology, Pasadena, California, USA
}

Received: 13 May 2011 - Published in Atmos. Chem. Phys. Discuss.: 20 May 2011

Revised: 25 August 2011 - Accepted: 10 September 2011 - Published: 21 September 2011

\begin{abstract}
Three-dimensional large-eddy simulations (LES) with detailed bin-resolved microphysics are performed to explore the diurnal variation of marine stratocumulus (MSc) clouds under clean and polluted conditions. The sensitivity of the aerosol-cloud-precipitation interactions to variation of sea surface temperature, free tropospheric humidity, largescale divergence rate, and wind speed is assessed. The comprehensive set of simulations corroborates previous studies that (1) with moderate/heavy drizzle, an increase in aerosol leads to an increase in cloud thickness; and (2) with non/light drizzle, an increase in aerosol results in a thinner cloud, due to the pronounced effect on entrainment. It is shown that for higher SST, stronger large-scale divergence, drier free troposphere, or lower wind speed, the cloud thins and precipitation decreases. The sign and magnitude of the Twomey effect, droplet dispersion effect, cloud thickness effect, and cloud optical depth susceptibility to aerosol perturbations (i.e., change in cloud optical depth to change in aerosol number concentration) are evaluated by LES experiments and compared with analytical formulations. The Twomey effect emerges as dominant in total cloud optical depth susceptibility to aerosol perturbations. The dispersion effect, that of aerosol perturbations on the cloud droplet size spectrum, is positive (i.e., increase in aerosol leads to spectral narrowing) and accounts for $3 \%$ to $10 \%$ of the total cloud optical depth susceptibility at nighttime, with greater influence in heavier drizzling clouds. The cloud thickness effect is negative (i.e., increase in aerosol leads to thinner cloud) for non/light drizzling cloud and positive for a moderate/heavy drizzling clouds; the cloud thickness effect contributes $5 \%$ to $22 \%$
\end{abstract}

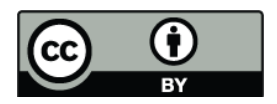

Correspondence to: J. H. Seinfeld (seinfeld@caltech.edu) of the nighttime total cloud susceptibility. Overall, the total cloud optical depth susceptibility ranges from $\sim 0.28$ to 0.53 at night; an increase in aerosol concentration enhances cloud optical depth, especially with heavier precipitation and in a more pristine environment. During the daytime, the range of magnitude for each effect is more variable owing to cloud thinning and decoupling. The good agreement between LES experiments and analytical formulations suggests that the latter may be useful in evaluations of the total cloud susceptibility. The ratio of the magnitude of the cloud thickness effect to that of the Twomey effect depends on cloud base height and cloud thickness in unperturbed (clean) clouds.

\section{Introduction}

Aerosols influence the microphysical properties of clouds and hence affect their radiative properties, amount, and lifetime (IPCC, 2007). This influence, termed the aerosol indirect effect on climate, is identified as one of the major uncertainties in a quantitative assessment of the anthropogenic radiative forcing of climate. Marine stratocumulus clouds (MSc) play a significant role in the Earth's radiation budget. Covering about one-third of the world's oceans (Warren et al., 1988), MSc are particularly susceptible to the effect of aerosol perturbations. These clouds are generally optically thick and exist at a low altitude, making them more effective at reflecting solar radiation (albedo is about 30-40\%, Randall et al., 1984) than at trapping terrestrial radiation. It has been estimated that a $6 \%$ increase of the albedo in MSc regions (equivalent to about a $0.2 \mathrm{~g} \mathrm{~kg}^{-1}$ moistening of the marine boundary layer (MBL), or an increase in cloud droplet number concentration $N_{\mathrm{d}}$ from 75 to $150 \mathrm{~cm}^{-3}$ ) could result

Published by Copernicus Publications on behalf of the European Geosciences Union. 
in a $1 \mathrm{Wm}^{-2}$ change in the net solar radiation at the top of the atmosphere (Stevens and Brenguier, 2009).

The complex interactions of the cloud system involve aerosol and cloud microphysics, atmospheric dynamics, radiation, and chemistry (e.g., Stevens and Feingold, 2009). Representations of the dynamic and thermodynamic state of MSc have been the subject of several reviews (e.g., Stevens, 2005, 2006) and numerous modeling studies. Mixed-layer models (MLMs, Lilly, 1968) couple cloud, radiation, and turbulence to describe the cloud-topped MBL (e.g., Turton and Nicholls, 1987; Bretherton and Wyant, 1997; Lilly, 2002; Wood, 2007; Sandu et al., 2009; Caldwell and Bretherton, 2009a; Uchida et al., 2010). Given surface and free-tropospheric thermodynamic conditions, bulk cloud properties, such as thickness, cloud liquid water path (LWP), and the MBL steady-state, can be determined by an MLM. The MLM framework represents a well-mixed MBL. Departures from well-mixed conditions are, however, common in situations of precipitation and during daytime.

To represent both MSc microphysics and dynamics, largeeddy simulations (LES) have become a powerful tool because of the ability to realistically represent the larger eddy turbulence field and the interactions of turbulence, cloud microphysics and radiation at an appropriate grid resolution. LES has been applied in many previous studies of MSc (e.g., Stevens et al., 1998, 2003, 2005; Stevens and Bretherton, 1999; Bretherton et al., 1999; Chlond and Wolkau, 2000; Jiang et al., 2002; Wang et al., 2003; Duynkerke et al., 2004; Lu and Seinfeld, 2005, 2006; Bretherton et al., 2007; Sandu et al., 2008; Savic-Jovcic and Stevens, 2008; Yamaguchi and Randall, 2008; Hill et al., 2008, 2009; Ackerman et al., 2009; Caldwell and Bretherton, 2009b; Wang and Feingold, 2009a,b; Wang et al., 2010; Uchida et al., 2010). Table 1 summarizes a number of studies that focus mainly on aerosol-cloud interactions in MSc; these address the LWP responses to changes in aerosol number and ambient environmental conditions. Atmospheric aerosols and meteorology each exert controls on cloudiness; the former governs the cloud micro-structure, while the latter provides the dynamic and thermodynamic state that controls cloud macro-structure (Stevens and Brenguier, 2009).

A number of effects of aerosol perturbations on cloud LWP, cloud lifetime, and precipitation have been predicted by numerical studies and, in some cases, identified by measurements. Overall, the causality that has been proposed for aerosol-cloud-precipitation interactions can be summarized as follows:

a. Twomey effect (assumes constant LWP): aerosol number concentration $\left(N_{\mathrm{a}}\right)$ increase $\rightarrow$ smaller, more numerous droplets $\rightarrow$ higher albedo (Twomey, 1977)

b. Albrecht effect (drizzling cloud): $N_{\mathrm{a}}$ increase $\rightarrow$ smaller, more numerous droplets $\rightarrow$ reduced collisioncoalescence $\rightarrow$ less precipitation $\rightarrow$ LWP increase $\rightarrow$ higher albedo (Albrecht, 1989) c. Drizzle-entrainment effect (drizzling cloud): $N_{\mathrm{a}}$ increase $\rightarrow$ smaller, more numerous droplets $\rightarrow$ reduced collision-coalescence $\rightarrow$ less precipitation $\rightarrow$ reduced below-cloud evaporative cooling and in-cloud latent heat release $\rightarrow$ higher turbulent kinetic energy (TKE) $\rightarrow$ stronger entrainment $\rightarrow$ LWP decrease $\rightarrow$ lower albedo (e.g., Lu and Seinfeld, 2005; Wood, 2007)

d. Sedimentation-entrainment effect (non-drizzling cloud): $\quad N_{\mathrm{a}}$ increase $\rightarrow$ smaller, more numerous droplets $\rightarrow$ reduced in-cloud sedimentation $\rightarrow$ increase of cloud water and evaporation in entrainment regions $\rightarrow$ stronger entrainment $\rightarrow$ LWP decrease $\rightarrow$ lower albedo (Ackerman et al., 2004; Bretherton et al., 2007; Hill et al., 2009)

e. Evaporation-entrainment effect (non-drizzling cloud): $N_{\mathrm{a}}$ increase $\rightarrow$ smaller, more numerous droplets $\rightarrow$ more efficient evaporation $\rightarrow$ higher TKE $\rightarrow$ stronger entrainment $\rightarrow$ LWP decrease $\rightarrow$ lower albedo (Wang et al., 2003; Xue and Feingold, 2006; Hill et al., 2008)

Meteorological conditions, such as free tropospheric humidity, large-scale divergence $(D)$, and sea surface temperature (SST), have strong impacts on cloud responses to aerosol perturbations. Several previous studies (Table 1) demonstrate the extent to which clouds are affected by aerosol perturbations under different meteorological conditions. Ackerman et al. (2004) found that the free troposphere moisture $\left(q_{\mathrm{ft}}\right)$ exerts a strong control on the precipitation rate through cloudtop entrainment, thus altering the balance between the competing effects of precipitation on LWP.

The effect of changes in the large-scale divergence, $D$, is consistent among the studies listed in Table 1, showing that under higher (lower) $D$, the MBL is shallower (deeper), resulting in thinner (thicker) cloud, lower (higher) LWP. Since $D$ is difficult to measure, its value is usually estimated.

The effect of changes in SST on MSc has been addressed in several studies. In the LES study of Lu and Seinfeld (2005), the initial temperature in the entire MBL was assumed to increase systematically with SST, and the MBL relative humidity was adjusted as well. It is found that with higher SST, the MBL deepens and cloud base rises, resulting in a thinner cloud with lower LWP in a short time period. And the MSc becomes less cloudy because of gradual dissipation. In the MLM study of Caldwell and Bretherton (2009a), however, as SST increases, the equilibrium cloud base and cloud top heights both increase due to increased entrainment through a weaker inversion, resulting in a thicker cloud with higher LWP. Therefore in response to a higher SST, shorter time scale and equilibrium responses have different effects on MSc.

Diurnal variation of MSc is the result of competition between cloud top longwave (LW) radiative cooling occurring both day and night, and daytime solar heating (Hill et al., 2008). During nighttime, cloud top LW cooling generates 
Table 1. Studies of aerosol-cloud interactions in MSc.

\begin{tabular}{|c|c|c|c|c|c|c|}
\hline & \multicolumn{3}{|c|}{ Nighttime } & \multicolumn{2}{|c|}{ Daytime } & \multirow{3}{*}{$\begin{array}{l}\text { Diurnal Mean* } \\
\text { Moderate/ Heavy }\end{array}$} \\
\hline & \multirow[t]{2}{*}{ Non-drizzling } & \multicolumn{2}{|c|}{ Drizzling } & \multirow[t]{2}{*}{ Non-drizzling } & \multirow{2}{*}{$\begin{array}{l}\text { Drizzling } \\
\text { Light }\end{array}$} & \\
\hline & & Light & Moderate/ Heavy & & & \\
\hline Ackerman et al. (2004) & & $\begin{array}{l}N_{\mathrm{a}} \uparrow \Longrightarrow \text { LWP } \downarrow \\
q_{\mathrm{ft}} \downarrow \Longrightarrow \mathrm{LWP} \downarrow\end{array}$ & $N_{\mathrm{a} \uparrow} \Longrightarrow P \downarrow \Longrightarrow \mathrm{LWP} \uparrow$ & & & \\
\hline Lu and Seinfeld (2005) & & $\begin{array}{l}N_{\mathrm{a}} \uparrow \Longrightarrow \mathrm{LWP} \downarrow \\
\mathrm{SST} \uparrow \Longrightarrow \mathrm{LWP} \downarrow \\
D \uparrow \Longrightarrow \mathrm{LWP} \downarrow\end{array}$ & $N_{\mathrm{a}} \uparrow \Longrightarrow P \downarrow \Longrightarrow \operatorname{LWP} \uparrow$ & $N_{\mathrm{a}} \uparrow \Longrightarrow$ LWP $\downarrow$ & & \\
\hline Wood (2007) & & & & & & $N_{\mathrm{a}} \uparrow \Longrightarrow H \downarrow$ or $\uparrow$ \\
\hline Sandu et al. (2008) & & & $\begin{array}{l}N_{\mathrm{a} \uparrow} \Longrightarrow P \downarrow \Longrightarrow \mathrm{LWP} \uparrow \\
D \uparrow \Longrightarrow \mathrm{LWP} \downarrow \\
q_{\mathrm{ft}} \downarrow \Longrightarrow \mathrm{LWP} \downarrow\end{array}$ & & $\begin{array}{l}N_{\mathrm{a} \uparrow} \fallingdotseq \mathrm{LWP} \downarrow \\
D \uparrow \Longrightarrow \mathrm{LWP} \downarrow \\
q_{\mathrm{ft}} \rightleftharpoons \mathrm{LWP} \downarrow\end{array}$ & \\
\hline Hill et al. $(2008,2009)$ & $N_{\mathrm{a}} \uparrow \Longrightarrow \mathrm{LWP} \downarrow$ & & & $N_{\mathrm{a}} \uparrow \Longrightarrow \mathrm{LWP} \downarrow$ & & \\
\hline Wang et al. (2010) & & & $N_{\mathrm{a}} \uparrow \Longrightarrow P \downarrow \Longrightarrow \operatorname{LWP} \uparrow$ & & $N_{\mathrm{a}} \uparrow \Longrightarrow \mathrm{LWP} \downarrow$ & \\
\hline Caldwell and Bretherton (2009a) & & $\begin{array}{l}N_{\mathrm{a} \uparrow} \Longrightarrow \mathrm{LWP} \downarrow \\
\mathrm{SST} \uparrow \Longrightarrow \mathrm{LWP} \uparrow\end{array}$ & & & & \\
\hline Summary & $N_{\mathrm{a}} \uparrow \Longrightarrow \mathrm{LWP} \downarrow$ & $\begin{array}{l}N_{\mathrm{a} \uparrow} \uparrow \mathrm{LWP} \downarrow \\
\mathrm{SST} \uparrow \Longrightarrow \mathrm{LWP} \downarrow \text { or } \uparrow \\
D \uparrow \Longrightarrow \mathrm{LWP} \downarrow \\
q_{\mathrm{ft}} \downarrow \Longrightarrow \mathrm{LWP} \downarrow\end{array}$ & $\begin{array}{l}N_{\mathrm{a} \uparrow} \Longrightarrow P \downarrow \Longrightarrow \mathrm{LWP} \uparrow \\
D \uparrow \Longrightarrow \mathrm{LWP} \downarrow \\
q_{\mathrm{ft}} \downarrow \Longrightarrow \mathrm{LWP} \downarrow\end{array}$ & $N_{\mathrm{a}} \uparrow \Longrightarrow \mathrm{LWP} \downarrow$ & $\begin{array}{l}N_{\mathrm{a} \uparrow} \Longrightarrow \mathrm{LWP} \downarrow \\
D \uparrow \Longrightarrow \mathrm{LWP} \downarrow \\
q_{\mathrm{ft}} \downarrow \mathrm{LWP} \downarrow\end{array}$ & $N_{\mathrm{a}} \uparrow \Longrightarrow H \downarrow$ or $\uparrow$ \\
\hline
\end{tabular}

$P$ is surface precipitation, $H$ is cloud thickness, $D$ is large-scale divergence rate, and $q_{\mathrm{ft}}$ is free tropospheric humidity. Light drizzle is defined as surface precipitation rate $<0.1 \mathrm{~mm}^{-1}$, and moderate/heavy drizzle $>0.1 \mathrm{~mm}^{-1}$ day $^{-1}$.

* Wood (2007) uses the downwelling shortwave radiation close to the annual diurnal mean value over the subtropical regions.

positive buoyancy in the cloud layer, which enhances incloud TKE and serves to mix the MBL. As the MBL is often well mixed, the cloud is supplied with moisture from the surface and becomes thicker despite the warmer and drier entrained air at cloud top. Under daytime conditions, absorption of solar radiation partially offsets the cloud top LW cooling and also warms the cloud layer throughout its depth. With the mixing of warmer entrained air and absorption of solar radiation, the cloud may become slightly warmer than the sub-cloud layer, and a thin stable layer may appear below the cloud base (Sandu et al., 2008). This stable layer could act to decouple the cloud from the sub-cloud layer, and result in a cutoff of the surface moisture supply and leads to a thinner cloud. Predicted daytime LWP is consistently smaller than that in nighttime. Also, daytime MBL is less sensitive to changing $N_{\mathrm{a}}$ than under nighttime conditions (e.g., Ackerman et al., 2004; Lu and Seinfeld, 2005), suggesting cloudradiation interactions are important in controlling the diurnal variation.

From a summary of the studies cited in Table 1, overall, non/light drizzling MSc and moderate/heavy drizzling MSc respond differently to changes in aerosol level since the dominant physical/dynamical mechanisms differ. Also, the MSc diurnal variation is distinct as a result of cloud-radiation interactions. MSc are found to be sensitive to changes in ambient conditions, e.g., SST, $D$, or $q_{\mathrm{ft}}$. Therefore the cloud response to aerosol perturbations also depends on the conditions governing the boundary layer.
Taken as a whole, a number of studies essentially cover the range of aerosol-cloud-precipitation interactions. No single study, however, covers the totality of aerosol and meteorological influences relative to a consistent base case. Highresolution LES simulations that investigate the full range of aerosol and meteorological variables are carried out in the present study. The meteorological factors investigated include SST, free-tropospheric humidity, large-scale subsidence rate, and wind speed. Diurnal variation is considered for non-precipitating as well as lightly and heavily precipitating conditions. In that sense, the present work can be viewed as a comprehensive, consistent retrospective of aerosol-MSc interactions. A second goal of the present study is to evaluate analytical formulations of total cloud optical depth susceptibility to aerosol perturbations, including the Twomey, droplet dispersion, cloud thickness effects. While such analytical formulations are generally based on simplistic assumptions, they offer the advantage of concisely encapsulating complex responses. If generally applicable, analytical formulations of MSc responses to aerosol perturbations offer promise for use in large-scale models. To the extent possible, each effect is quantitatively evaluated from LES experiments to enable comparison with the analytical formulations. The present work therefore also provides an indication of the extent to which analytical formulations of total cloud susceptibility to aerosol perturbations can be evaluated with LES. 


\section{Cloud susceptibility to aerosol perturbations}

Before proceeding to the numerical study, it is useful to address MSc aerosol-cloud relationship from a simplified analytical point of view. Analytical relationships, if shown to be valid by comparison with a more vigorous LES approach, can be effective in representing aerosol-cloud-precipitation interaction response. Considering the change of cloud radiative properties in response to a change in aerosol number concentration, $N_{\mathrm{a}}$, the relationship between adiabatic cloud optical thickness, $\tau_{\mathrm{ad}}$, and adiabatic cloud droplet number concentration, $N_{\text {ad }}$, can be expressed (Brenguier et al., 2000):

$\tau_{\mathrm{ad}}=\frac{9}{10}\left(\frac{4}{3} \pi\right)^{\frac{1}{3}} l_{o}^{\frac{2}{3}}\left(k N_{\mathrm{ad}}\right)^{\frac{1}{3}} H^{\frac{5}{3}}$,

where $l_{0}=C_{\mathrm{w}} / \rho_{\mathrm{w}}, \rho_{\mathrm{w}}$ is the density of water, $C_{\mathrm{w}}$ is the moist adiabatic condensation coefficient, $k$ is a parameter related to the droplet spectrum shape, which is inversely proportional to the droplet distribution breadth, and $H$ is cloud thickness. The range of $k$ is 1 in the limit of a monodisperse size distribution and approaches 0 for a very wide distribution. In the presence of cloud top entrainment and water loss through precipitation, the cloud droplet profile tends to be sub-adiabatic. A sub-adiabaticity parameter $f$ can be defined to include the effects of entrainment and precipitation in drying out the cloud relative to the adiabatic case. Equation (1) can be generalized (W. Conant, unpublished, 2005) as

$\tau=\frac{9}{10}\left(\frac{4}{3} \pi\right)^{\frac{1}{3}} l_{o}^{\frac{2}{3}} f^{\frac{(2+m)}{3}}\left(k N_{\mathrm{ad}}\right)^{\frac{1}{3}} H^{\frac{5}{3}}$,

where $f$ is 1 under adiabatic conditions, and approaches 0 as the degree to which the profile is sub-adiabatic increases. The parameter $m$ describes the microphysical impacts of mixing between the cloudy air and the relatively dry/warm free tropospheric air. $m=1$ corresponds to the limit of inhomogeneous mixing, in which the turbulent mixing is relatively slow and all droplets in the entrained air evaporate, resulting in reduction of $N_{\mathrm{d}}$ and broadening of the droplet spectrum. $m=0$ corresponds to the limit of homogeneous mixing, in which the timescale of turbulent mixing is much shorter than that at which droplets respond to the fresh ambient air. In this limit, all droplets experience the same degree of sub-saturation and evaporate together; thus $N_{\mathrm{d}}$ remains constant as all droplets shift to smaller sizes.

From Eq. (2), the impact of changes in aerosol number concentration on cloud optical depth (total cloud susceptibility) can be expressed as follows:

$\frac{d \ln \tau}{d \ln N_{\mathrm{a}}}=\frac{1}{3}\left(\frac{d \ln N_{\mathrm{ad}}}{d \ln N_{\mathrm{a}}}+\frac{d \ln k}{d \ln N_{\mathrm{a}}}+5 \frac{d \ln H}{d \ln N_{\mathrm{a}}}+(2+m) \frac{d \ln f}{d \ln N_{\mathrm{a}}}\right)$.

\subsection{Twomey effect}

From the above equation, $d \ln N_{\text {ad }} / d \ln N_{\text {a }}$ represents the socalled Twomey effect. An analytical relationship between $N_{\text {ad }}$ and $N_{\mathrm{a}}$, modified from that derived by Twomey (1959), is

$N_{\mathrm{ad}}=N_{\mathrm{a}}^{\frac{2}{k_{\mathrm{s}}+2}}\left(\frac{c w^{\frac{3}{2}}}{k_{\mathrm{s}} B\left(\frac{k_{\mathrm{s}}}{2}, \frac{3}{2}\right)}\right)^{k_{\mathrm{s}} /\left(k_{\mathrm{s}}+2\right)}$,

where $B$ is the beta function, $w$ is updraft velocity at cloud base, $k_{\mathrm{s}}$ is a parameter related to the exponent in an assumed power-law aerosol size distribution, and $c$ is a compositiondependent parameter that relates the aerosol size distribution to the supersaturation spectrum. The updraft velocity is the single dynamical factor considered in the analytical expression. From Eq. (4),

$\frac{d \ln N_{\mathrm{ad}}}{d \ln N_{\mathrm{a}}}=\frac{2}{k_{\mathrm{s}}+2}$.

Values of $k_{\mathrm{s}}$ range from 0.3 to 1.4 (empirical constants for cloud condensation nuclei, $\mathrm{CCN}$, at $1 \%$ supersaturation, from Pruppacher and Klett, 1997). For that range, $d \ln N_{\mathrm{ad}} / d \ln N_{\mathrm{a}}$ varies from about $0.6-0.9$ under adiabatic conditions. Shao and Liu (2009) compared $d \ln N_{\mathrm{ad}} / d \ln N_{\mathrm{a}}$ predicted by Eq. (5) with in situ measurements (values of $0.25-0.85)$. Differences in the value of $d \ln N_{\mathrm{ad}} / d \ln N_{\mathrm{a}}$ between the analytical expression and ambient measurements can be attributed to (1) activation effect: adding aerosols, for example, into a marine aerosol background reduces the ability of aerosols to act as $\mathrm{CCN}$, and (2) adiabaticity influence: the variability of the adiabaticity (cloud dilution state) from different meteorological conditions between clean and polluted cases.

\subsection{Dispersion effect}

The second term $d \ln k / d \ln N_{\mathrm{a}}$ expresses the effect of changes in $N_{\mathrm{a}}$ on the cloud droplet size distribution. Dispersion in the droplet distribution is related to aerosol composition (e.g., Feingold and Chuang, 2002), microphysics (e.g., collisioncoalescence), and dynamics (e.g., entrainment mixing, updraft velocity) (Wood et al., 2002; Lu and Seinfeld, 2006). It is noted from observational data (Martin et al., 1994; Ackerman et al., 2000; Liu and Daum, 2002) that the dispersion forcing would offset the cooling from the Twomey effect as the competition for water vapor in the relatively polluted, condensation-dominated regime leads to spectral broadening and negative dispersion effect (Feingold and Siebert, 2009). Accounting for the parameterization of dispersion effect in GCMs leads to a reduction in the magnitude of the predicted Twomey effect (Rotstayn and Liu, 2003, 2009). By contrast, an opposite trend is found in the LES study of Lu and Seinfeld (2006). For a drizzling cloud, increasing $N_{\mathrm{a}}$ leads to 
Table 2. Sign and magnitude of each term in Eq. (3) from previous studies.

\begin{tabular}{|c|c|c|c|c|}
\hline & $\frac{\Delta\left(\ln N_{\mathrm{d}}\right)}{\Delta\left(\ln N_{\mathrm{a}}\right)}$ & $\frac{\Delta(\ln k)}{\Delta\left(\ln N_{\mathrm{d}}{ }^{*}\right)}$ & $\frac{\Delta(\ln H)}{\Delta\left(\ln N_{\mathrm{d}}{ }^{*}\right)}$ & $\frac{\Delta(\ln \tau)}{\Delta\left(\ln N_{\mathrm{a}}\right)}$ \\
\hline Measurement & $\begin{array}{l}0.6-0.9^{\mathrm{a}} \\
0.25-0.85^{\mathrm{b}}\end{array}$ & $\begin{array}{l}-0.2^{\mathrm{c}} \\
-0.14^{\mathrm{d}}\end{array}$ & & \\
\hline LES & $0.91^{\mathrm{e}}($ constant LWP) & $\begin{array}{l}\sim 0.03 \text { (light drizzle) }^{\mathrm{f}} \\
\sim 0.2 \text { (heavy drizzle) }^{\mathrm{f}}\end{array}$ & $\begin{aligned}{\frac{\partial(\ln L W P)}{\partial\left(\ln N_{\mathrm{a}}\right)}}^{\mathrm{e}}= & -0.1(\text { clean }) \\
& -0.03 \text { (polluted) }\end{aligned}$ & $\begin{array}{l}0.22(\text { clean })^{\mathrm{e}} \\
0.28{\text { (polluted })^{\mathrm{e}}}\end{array}$ \\
\hline Other & & & $\begin{array}{l}\text { cloud base }>400 \mathrm{~m} \text { : thinning } \\
\text { cloud base }<400 \mathrm{~m} \text { : thickening }\end{array}$ & $0.28^{\mathrm{h}}$ \\
\hline
\end{tabular}

* Note $N_{\mathrm{d}}$ is applied rather than $N_{\mathrm{a}}$.

a Pruppacher and Klett (1997)

b Shao and Liu (2009), based on in situ measurements.

c Rotstayn and Liu (2003), including measurements from FIRE, SOCEX, ACE1, ASTEX, SCMS, INDOEX, MAST, etc.

d Ackerman et al. (2000)

${ }^{\text {e }}$ Lu and Seinfeld (2005): LES based on sounding profiles from FIRE and ASTEX. Note LWP is applied rather than $H$.

${ }^{\mathrm{f}} \mathrm{Lu}$ and Seinfeld (2006): LES based on sounding profiles from FIRE and ASTEX.

g Wood (2007): obtained by MLM and analytical formulations.

${ }^{\mathrm{h}}$ Hill et al. (2009) Table 4.

spectrum narrowing (larger $k$ ) because smaller droplets suppress precipitation and lead to (1) less spectral broadening by suppressed collision-coalescence and (2) more spectral narrowing by droplet condensational growth at higher updraft velocity due to stronger TKE (Lu and Seinfeld, 2006). In that case, the dispersion effect enhances the Twomey effect. This trend is evident from the calculation based on in situ measurements by Miles et al. (2000) and individual ship tracks in Lu et al. (2007).

\subsection{Cloud thickness effect}

The third term in Eq. (3), $d \ln H / d \ln N_{\mathrm{a}}$, expresses the sensitivity of cloud thickness to changes in $N_{\mathrm{a}}$, for which Wood (2007) derived an analytical formulation and applied a MLM to quantify the response of cloud thickness to perturbed $N_{\mathrm{d}}$ under different environmental conditions. Wood (2007) showed that the MSc cloud thickness response is determined by a balance between the moistening/cooling of the MBL resulting from precipitation suppression and drying/warming resulting from enhanced entrainment due to increased TKE. The drying and warming effect (cloud thinning) counteracts the moistening/cooling effect (cloud thickening). Also using the MLM model, Pincus and Baker (1994) predicted that cloud thickness $(H)$ increases with $N_{\mathrm{d}}$, especially at lower droplet concentration. Unlike the Pincus and Baker (1994) result that $H$ is determined primarily by cloud top height, Wood (2007) found the cloud-base height to be the single most important determinant in affecting cloud thickness. If the cloud base height is lower (higher) than $400 \mathrm{~m}$, increasing $N_{\mathrm{d}}$ leads to cloud thickening (thinning), which corresponds to LWP increase (decrease). The argument is that for an elevated cloud base, more evaporation occurs before precipitation reaches the surface, leading to two effects (Wood,
2007): (i) more sub-cloud evaporation limits the moistening/cooling of the MBL resulting from precipitation suppression, while allowing suppressed precipitation to increase the entrainment with increasing $N_{\mathrm{d}}$, and (ii) sub-cloud evaporation has a stronger effect on turbulence than in-cloud latent heating; therefore enhanced sub-cloud evaporation increases the leverage of changes in cloud base precipitation on entrainment.

\subsection{Adiabaticity effect}

The term, $d \ln f / d \ln N_{\mathrm{a}}$, can be termed the adiabaticity effect, accounting for the effect of liquid water depletion due to entrainment mixing and precipitation on cloud optical depth. This term cannot be evaluated separately from the other terms; the effect of sub-adiabaticity is intertwined with all the previous effects discussed. The qualitative effect of entrainment mixing on cloud behavior has been discussed in Sect. 1 (effects (c), (d), and (e)).

Some of these individual effects have been estimated in several previous studies (Table 2), including analytical solutions, in situ measurements, satellite data, and LES. We will subsequently estimate the magnitudes for each effect from LES simulation.

\section{Model description}

\subsection{Numerical model}

In this study we employ the Weather Research and Forecasting (WRF) model V3.1.1 as a 3-D LES model. Several studies (e.g., Moeng et al., 2007; Wang and Feingold, 2009a,b; Wang et al., 2009) have used the WRF model for LES experiments and found the results are in good agreement with 
observations and other LES studies. Therefore we apply the WRF model as the LES dynamic framework. Note that Wang et al. (2009) compared WRF LES with other models for the same intercomparison case study (Ackerman et al., 2009). Most model variables and derived quantities (e.g., total water mixing ratio, liquid water potential temperature, LWP, buoyancy flux, total water flux, TKE, and cloud fraction) lie within the corresponding ensemble range in Ackerman et al. (2009); however, the variance of vertical velocity and belowcloud rain rate were underestimated by WRF LES for the case they considered. A detailed bin-resolved microphysical scheme (Geresdi, 1998; Rasmussen et al., 2002; Xue et al., 2010 ) is employed in the WRF model. In the bin microphysical scheme, aerosol number, cloud drop mass, and cloud drop number are computed over a size-resolved spectrum, predicting both cloud drop mass and number concentration following the moment-conserving technique (Tzivion et al., 1987, 1989; Reisin et al., 1996). Cloud drops are divided into 36 size bins with radii ranging from $1.56 \mu \mathrm{m}$ to $6.4 \mathrm{~mm}$ and with mass doubling between bins. The masses for the first bin and the 36 th bin are $1.5979 \times 10^{-14}$ and $1.098 \times 10^{-3} \mathrm{~kg}$, respectively. In this study, the cutoff radius between cloud drop and rain drop size is taken to be $\sim 40 \mu \mathrm{m}$. The aerosols are divided into 40 size bins between 0.006 to $66.2 \mu \mathrm{m}$.

\subsection{Microphysical processes}

The microphysical processes include aerosol activation, drop condensation/evaporation, collision-coalescence, collisional breakup, and sedimentation. The aerosol size distribution is taken to be a single mode lognormal size distribution. Aerosol activation (or cloud droplet activation) occurs when the ambient supersaturation exceeds the critical supersaturation $\left(S_{\mathrm{c}}\right)$ for the given particle size. A hygroscopicity parameter $\kappa$, which describes the relationship between dry particle diameter and cloud condensation nuclei activity, is used to represent the composition-dependence of the solution water activity (Petters and Kreidenweis, 2007),

$S_{\mathrm{c}}\left(D_{d}\right)=\frac{D_{d}^{3}-D_{\mathrm{a}}^{3}}{D_{d}^{3}-D_{\mathrm{a}}^{3}(1-\kappa)} \exp \left(\frac{4 \sigma_{\frac{\mathrm{a}}{\mathrm{a}}} M_{\mathrm{w}}}{R T \rho_{\mathrm{w}} D_{d}}\right)-1$,

where $D_{d}$ is droplet diameter, $D_{\mathrm{a}}$ is aerosol dry diameter, $\sigma \frac{\mathrm{s}}{2}$ is the surface tension of the solution/air interface, $M_{\mathrm{w}}$ is the molecular weight of water, and $\rho_{\mathrm{w}}$ is the density of water. For the present study, the aerosol is assumed to be ammonium sulfate, for which $\kappa$ is set to the constant value 0.615 (Petters and Kreidenweis, 2007).

The aerosol number concentration is held constant in the present study. The activated droplet number at each time is calculated by the difference between the particle number that would be activated at the diagnosed supersaturation and the pre-existing droplet number, consistent with several previous studies (e.g., Stevens et al., 1998; Lu and Seinfeld, 2005, 2006; Sandu et al., 2008). Diffusional growth and evaporation of water drops are described following the vapor diffu-
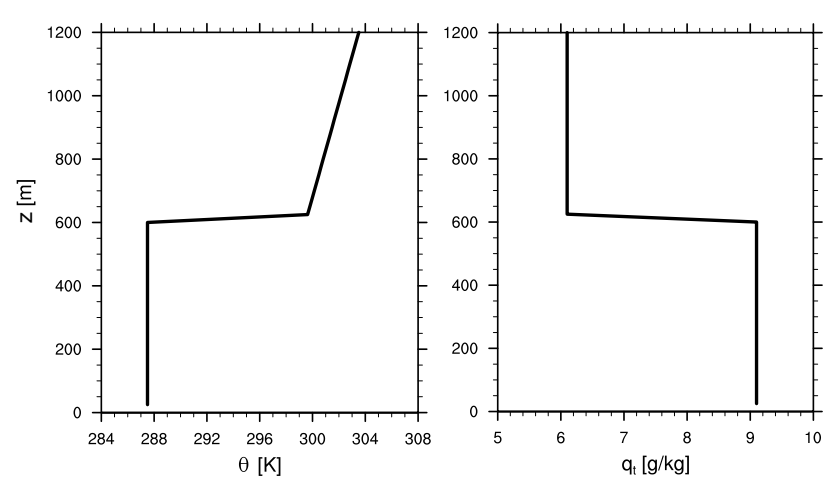

Fig. 1. Initial sounding profile (potential temperature $\theta$ and total water mixing ratio $q_{t}$ ) for the MSc of Control case.

sion equation (Pruppacher and Klett, 1997). The Best and Bond number approach is used to calculate the terminal velocity of water drops (Pruppacher and Klett, 1997). The efficiencies of collision-coalescence between drops are derived using the data of Hall (1980) to calculate the kernel function. The collisional breakup of water drops is included following Feingold et al. (1988).

\subsection{Other processes}

Surface latent and sensible heat fluxes are calculated from local wind speed and the difference in specific humidity/potential temperature between the ocean and the air just above the ocean surface, following the Monin-Obukhov scheme. A 3-D turbulence scheme with 1.5-order turbulent kinetic energy (TKE) closure (Deardorff, 1980) is applied to prognose TKE. The Rapid Radiative Transfer Model (RRTM; Mlawer et al., 1997) with 16 LW bands is utilized to calculate LW radiative fluxes. The correlated-k method is used to simulate the cloud-top radiative cooling and heating rates. Shortwave radiation is represented using the Dudhia scheme (1989) to include solar flux, shortwave absorption and scattering in clear air, and reflection and absorption in cloud layers. A damping layer of $300 \mathrm{~m}$ thickness is employed in the upper boundary of domain for absorbing gravity wave energy to minimize the unphysical wave reflection off the upper boundary of the domain. Periodic boundary conditions in both $\mathrm{x}$ - and $\mathrm{y}$ - directions are assumed in the simulations. The monotonic flux limiter is applied to the basic advection scheme for scalar transport, as suggested by Wang et al. (2009) to avoid overestimates of cloud water and precipitation in cloud-scale simulations.

\section{Experimental design}

The WRF model with detailed bin microphysics is used to simulate an idealized MSc case for $30 \mathrm{~h}$ to cover a diurnal cycle. The aerosol is assumed to be fully soluble 

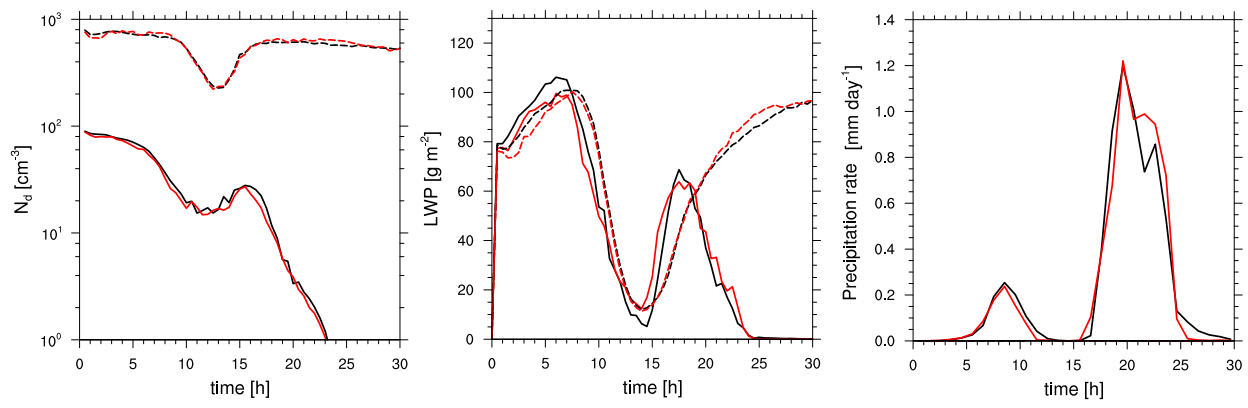

Fig. 2. Time evolution of $N_{\mathrm{d}}$, LWP, and surface precipitation rate under different domain size: $2.5 \times 2.5 \mathrm{~km}^{2}$ (black) and $1 \times 1 \mathrm{~km}^{2}(\mathrm{red})$; under different $N_{\mathrm{a}}$ : clean (solid line) and polluted (dashed line) cloud.

Table 3. Summary of simulated cases.

\begin{tabular}{lllllll}
\hline & $N_{\mathrm{a}}\left(\mathrm{cm}^{-3}\right)$ & Domain $\left(\mathrm{km}^{2}\right)$ & $\mathrm{SST}(\mathrm{K})$ & $q_{\mathrm{ft}}\left(\mathrm{g} \mathrm{kg}^{-1}\right)$ & $D\left(10^{-6} \mathrm{~s}^{-1}\right)$ & $U, V\left(\mathrm{~ms}^{-1}\right)$ \\
\hline Control & $100,200,1000$ & $1 \times 1,2.5 \times 2.5$ & 288 & 6.1 & 5.5 & $x:-1, y: 6$ \\
SST290, SST292 & 100,1000 & $1 \times 1$ & 290,292 & & & \\
QFT3, QFT1 & 100,1000 & $1 \times 1$ & & $3.1,1.1$ & & $3.0,8.0$ \\
DIV3, DIV8 & 100,1000 & $1 \times 1$ & & & $x:-4, y: 10$ \\
WIND & 100,1000 & $1 \times 1$ & & & & \\
\hline
\end{tabular}

ammonium sulfate following lognormal distribution with mean radius of $0.1 \mu \mathrm{m}$ and geometric standard deviation of 1.5. The initial sounding profile for the control case (Fig. 1) is loosely based on the First International Satellite Cloud Climatology Project Regional Experiment (FIRE I; Duynkerke et al., 2004) in July 1987, with the total water mixing ratio decreased by $0.5 \mathrm{~g} \mathrm{~kg}^{-1}$ for a moderately drizzling $(0.1-$ $1 \mathrm{~mm}$ day $^{-1}$ ) cloud. The case simulated is a shallow boundary layer with a depth of $\sim 600 \mathrm{~m}$ and topped with a $12 \mathrm{~K}$ and $-3 \mathrm{~g} \mathrm{~kg}^{-1}$ temperature and moisture inversion, respectively. The Coriolis parameter is $8 \times 10^{-5} \mathrm{~s}^{-1}\left(33.5^{\circ} \mathrm{N}, 119.5^{\circ} \mathrm{W}\right)$. Other initial conditions are similar to those in Hill et al. (2009). The nominal sea surface temperature (SST) is set to $288 \mathrm{~K}$, and surface pressure is assumed to be constant at $1012.5 \mathrm{mb}$. The wind field is $-1 \mathrm{~ms}^{-1}$ in the $\mathrm{x}$-direction and $6 \mathrm{~ms}^{-1}$ in the y-direction. The nominal large-scale divergence rate $(D), 5.5 \times 10^{-6} \mathrm{~s}^{-1}$, is given to prescribe the subsidence rate $W_{\text {sub }}=-D z$, where $z$ is the height above surface. The initial temperature field is perturbed pseudorandomly by an amplitude of $0.1 \mathrm{~K}$ to accelerate the spinup of turbulence. Results are not sensitive to this amplitude. Both LW and SW radiation are considered. Radiative forcing is computed every time step. In order to avoid MSc dissipation due to strong solar radiation in summer, winter conditions are chosen for SW radiation.

Three Control simulations are performed within a $2.5 \mathrm{~km} \times 2.5 \mathrm{~km} \times 1.6 \mathrm{~km}$ domain for $30 \mathrm{~h}$. The grid spacing is $20 \mathrm{~m}$ vertically and $50 \mathrm{~m}$ horizontally, with a $0.5 \mathrm{~s}$ time step. Aerosol number concentrations $\left(N_{\mathrm{a}}\right)$ of 100,200 , and
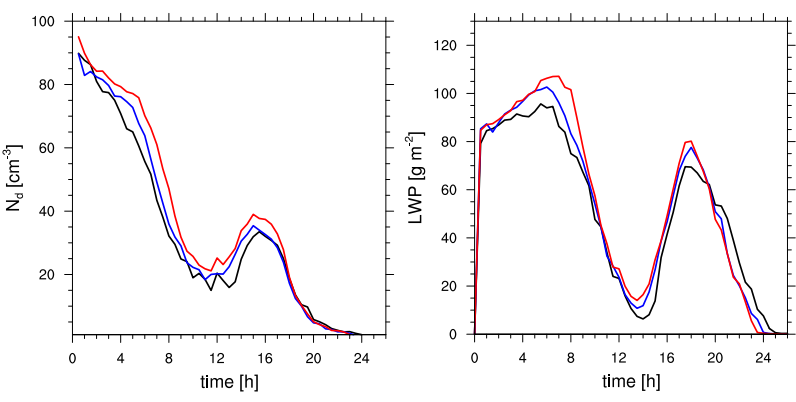

Fig. 3. Time evolution of $N_{\mathrm{d}}$ and LWP under different vertical spacing: $20 \mathrm{~m}$ (black), $10 \mathrm{~m}$ (blue), and $5 \mathrm{~m}$ (red) for clean condition.

$1000 \mathrm{~cm}^{-3}$ are taken to correspond to clean, semi-polluted, and polluted cases, respectively. For computational efficiency, sensitivity studies are performed over a smaller horizontal domain size, $1 \mathrm{~km}$ in $\mathrm{x}$ - and $\mathrm{y}$-directions. Figure 2 shows that the cloud bulk properties and surface precipitation rate of larger $(2.5 \mathrm{~km} \times 2.5 \mathrm{~km})$ and smaller $(1 \mathrm{~km} \times 1 \mathrm{~km})$ domain sizes are similar. Finer vertical spacings $(5$ and $10 \mathrm{~m})$ are also examined (Fig. 3) for the clean case, showing that the $N_{\mathrm{d}}$ and LWP responses are robust with different vertical spacings, although both $N_{\mathrm{d}}$ and LWP are higher with finer vertical resolution. This agrees with the results of Hill et al. (2009) that LWP responses are insensitive to the resolution tests (grid size $20 \mathrm{~m} \times 20 \mathrm{~m} \times 10 \mathrm{~m}$ versus $40 \mathrm{~m} \times 40 \mathrm{~m} \times 20 \mathrm{~m}$ ). Since our focus is on the directional changes of cloud properties in response to different ambient conditions, the smaller 

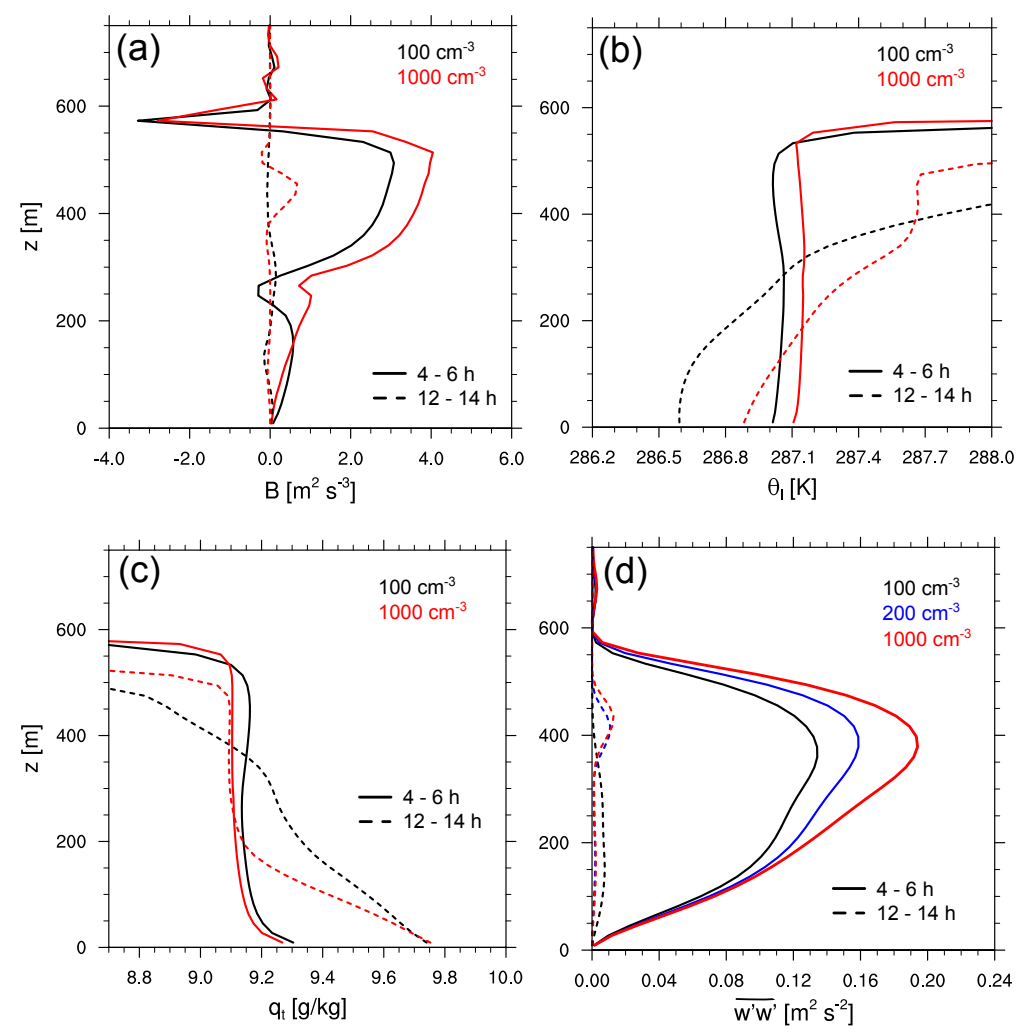

Fig. 4. Vertical profile averaged over 4-6h (solid line) and 12-14 h (dashed line) of (a) mean buoyancy flux, $B=\frac{g}{\overline{\theta_{v}}} \overline{w^{\prime} \theta_{v}{ }^{\prime}} \times 10^{-4}$, where $\theta_{v}$ is virtual potential temperature, (b) mean liquid water potential temperature $\theta_{l}$, (c) mean total water mixing ratio $q_{t}$, and (d) mean vertical velocity variance of clean (black), semi-polluted (blue), and polluted (red) cloud.

domain with $20 \mathrm{~m}$ vertical spacing is sufficient for sensitivity studies. Four significant environmental variables that control the structure of the MSc are considered: SST, free tropospheric water vapor mixing ratio $\left(q_{\mathrm{ft}}\right)$, large-scale divergence rate $(D)$, and wind speed $(U$ and $V)$. The lower BL stability is controlled mainly by SST (Klein and Hartmann, 1993). The humidity above the BL determines the drying/warming effect through entrainment. The large-scale divergence $D$ affects the subsidence rate. The wind speed is considered, as it mainly affects the surface fluxes.

The simulations performed are listed in Table 3. In cases SST290 and SST292, SST is increased by $2 \mathrm{~K}$ and $4 \mathrm{~K}$, respectively. In cases QFT3 and QFT1, the free tropospheric water vapor mixing ratio is decreased to 3.1 and $1.1 \mathrm{~g} \mathrm{~kg}^{-1}$, respectively; the temperature profile remains unchanged. In cases DIV3 and DIV8, the large scale divergence rate is set to $3.0 \times 10^{-6}$ and $8.0 \times 10^{-6} \mathrm{~s}^{-1}$, respectively, with all else unchanged. In WIND case, the initial wind speed is set to $-4 \mathrm{~ms}^{-1}$ in the $\mathrm{x}$-direction and $10 \mathrm{~ms}^{-1}$ in the y-direction for the entire boundary layer, stronger than the Control case. Both clean and polluted scenarios are simulated for each condition.

\section{Results}

\subsection{Control case}

The simulations start at 00:00 h local time. During nighttime, cloud top LW radiative cooling generates positive buoyancy in the cloud layer (Fig. 4a), which enhances TKE and mixing, destabilizing the MBL and increasing the cloud top entrainment. Cloud-top entrainment tends to raise the cloud base by diluting the cloud with warm and dry air, but it also tends to lift cloud-top height (e.g., Randall, 1984). With stronger mixing, water vapor from the surface is transported to upper layers more efficiently, causing the difference between water vapor mixing ratio at the reference level and saturation mixing ratio at the surface to increase, and thus leading to a higher surface moisture flux. This results in a moister cloud layer, increased cloud thickness and LWP at nighttime (Fig. 5a, b). For the clean case $\left(N_{\mathrm{a}}=100 \mathrm{~cm}^{-3}\right)$, measurable surface precipitation begins at $5 \mathrm{~h}$ as LWP increases, proceeding from light drizzle (surface rain rate $<0.1 \mathrm{~mm}$ day $^{-1}$ ) to moderate drizzle $\left(0.1-1 \mathrm{~mm} \mathrm{day}^{-1}\right)$ after $7 \mathrm{~h}$. During the daytime, the heating due to cloud absorption of solar radiation partially offsets the cloud top LW cooling, stabilizing the MBL. Heating of the cloudy layer via SW absorption acts to 

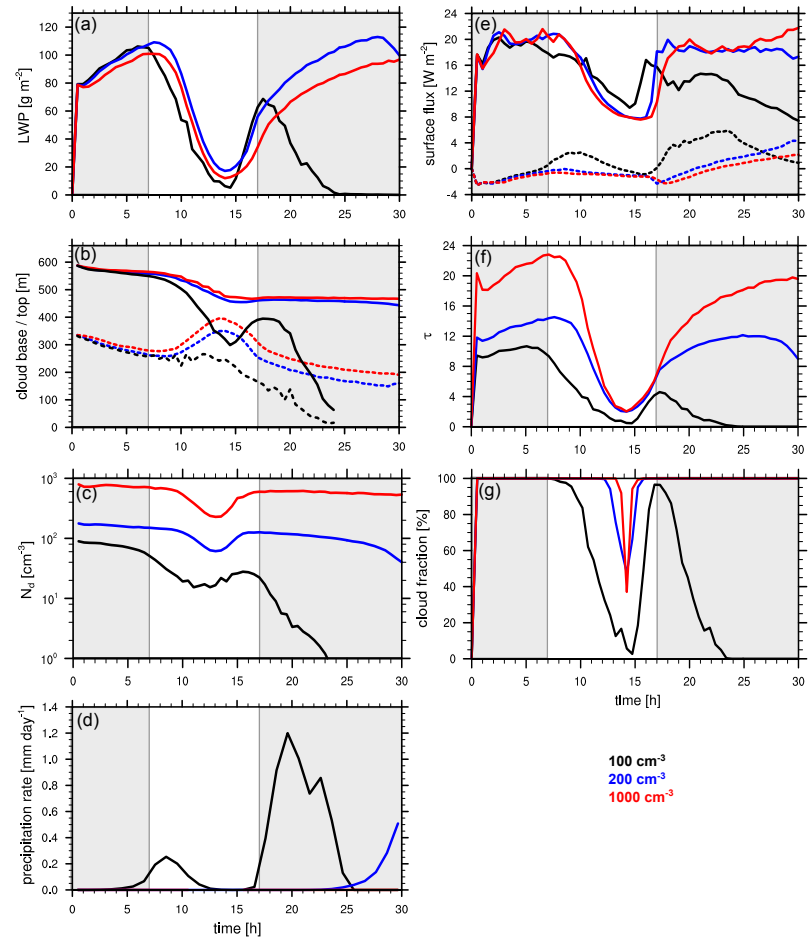

$100 \mathrm{~cm}^{-3}$
$200 \mathrm{~cm}^{-3}$
$1000 \mathrm{~cm}^{-3}$

Fig. 5. Time evolution of clean $\left(N_{\mathrm{a}}=100 \mathrm{~cm}^{-3}\right.$, black), semipolluted $\left(N_{\mathrm{a}}=200 \mathrm{~cm}^{-3}\right.$, blue $)$, and polluted $\left(N_{\mathrm{a}}=1000 \mathrm{~cm}^{-3}\right.$, red) cloud $\left(2.5 \times 2.5 \mathrm{~km}^{2}\right.$ horizontal domain): (a) average LWP; (b) average cloud top (solid line) and cloud base (dashed line) height, where the cloudy grid is defined as grid with cloud water mixing ratio $>0.01 \mathrm{~g} \mathrm{~kg}^{-1}$; (c) cloud droplet number concentration $N_{\mathrm{d}}$, averaged over the cloudy grid; (d) surface precipitation rate, hourly averaged; (e) domain average surface latent (solid line) and sensible (dashed line) heat flux; (f) average cloud optical depth; (g) cloud fraction, defined by cloud optical depth $>2$. Gray regions are for the nighttime conditions $(0-7 \mathrm{~h}$ and $17-30 \mathrm{~h})$, while write regions are for the daytime conditions $(7-17 \mathrm{~h})$.

thin the cloud; surface precipitation is suppressed after $12 \mathrm{~h}$ (Fig. 5d). Also, the MSc becomes decoupled from the subcloud layer as the cloud gets slightly warmer than the subcloud layer and a stable layer occurs at the cloud base. In the $\theta_{l}$ and $q_{t}$ daytime profiles (Fig. $4 \mathrm{~b}, \mathrm{c}$ ), it is shown that the moister and cooler surface air is not transported to the cloud layer effectively (12-14 h). As the cloud continues to warm, the LWP decreases, attaining a minimum at $\sim 14 \mathrm{~h}$. It is noted, however, that the solar heating is likely overestimated with the Dudhia SW radiation scheme and leads to overly reduced daytime cloud water.

After $14 \mathrm{~h}$, cloud top height begins to increase again due to a decrease in downwelling SW radiation, and drizzle appears after $\sim 16 \mathrm{~h}$ (Fig. $5 \mathrm{~d}$ ). In the clean case, the drizzle evaporation below the cloud can moisten and cool the subcloud layer, increasing the relative humidity of the sub-cloud air, lowering the cloud lifting condensation level, hence low- ering cloud base (Lu and Seinfeld, 2005). Also, the cloudtop entrainment decreases in the presence of drizzle, therefore the cloud top falls. The decreased entrainment drying/warming increases the MBL relative humidity and leads to a lower lifting condensation level. Therefore, more raindrops are likely to reach the surface before evaporating in the sub-cloud layer. As the surface precipitation increases during the second night, the cloud becomes optically thinner (Fig. 5f) and cloud top LW cooling decreases, allowing subsidence to compress the MBL. The cloud eventually disappears at $\sim 24 \mathrm{~h}$.

Proceeding from clean to semi-polluted $\left(N_{\mathrm{a}}=200 \mathrm{~cm}^{-3}\right)$ condition, more numerous and smaller cloud droplets undergo less efficient collision-coalescence, which leads to a suppression of precipitation. Therefore, the semi-polluted case is nonprecipitating for the first $25 \mathrm{~h}$. The precipitation suppression at nighttime results in higher TKE, because in the presence of precipitation, drizzle formation leads to stabilization of the sub-cloud layer through evaporative cooling and moistening. The cooling and moistening below the cloud leads to weaker turbulence intensity and inhibition of deeper mixing, and may also lower the cloud base (Lu and Seinfeld, 2005). During the daytime this can partially offset the warming of the cloud base due to absorption of solar radiation and counteract the tendency for the cloud base to rise (Sandu et al., 2008). The existence of drizzle reduces the buoyancy, stabilizes the MBL, decreases the TKE, and reduces the entrainment strength. As a result, precipitation suppression due to increased $N_{\mathrm{a}}$ increases the buoyancy fluxes and TKE, destabilizes the MBL, enhances the cloud-top entrainment (as shown in pathway (c)), and establishing a wellmixed MBL. This is consistent with previous findings (e.g., Stevens et al., 1998; Ackerman et al., 2004; Lu and Seinfeld, 2005; Wood, 2007).

From 10 to $15 \mathrm{~h}$, the semi-polluted cloud thins due to solar heating. With a stabilized MBL and decreased TKE during the daytime, the cloud top falls by $80 \mathrm{~m}$ due to reduced cloud top entrainment. As the MBL gradually warms with SW heating, the relative humidity in the MBL decreases, causing the cloud base to rise by $100 \mathrm{~m}$. Consequently, LWP decreases as cloud thins. During the second night, the LWP of the semi-polluted cloud increases with weaker SW heating, exceeding $110 \mathrm{gm}^{-2}$, and drizzle appears in the last $5 \mathrm{~h}$ of the simulation.

Proceeding from semi-polluted to polluted condition $\left(N_{\mathrm{a}}=1000 \mathrm{~cm}^{-3}\right)$, stronger TKE is generated from sedimentation-entrainment and evaporation-entrainment feedbacks by numerous smaller cloud droplets (as discussed previously in Sect. 1 pathway (d) and (e)), resulting in a drier cloud layer and less LWP, as compared to the semi-polluted case. This is evident from the vertical profile of vertical velocity variance $\left(\left(\overline{w^{\prime} w^{\prime}}\right)\right.$, a measure of strength of turbulent mixing, Fig. 4d). This result agrees with that of Ackerman et al. (2004), in that the entrainment increases with increasing $N_{\mathrm{a}}$ in all simulations. Also, the LWP is 

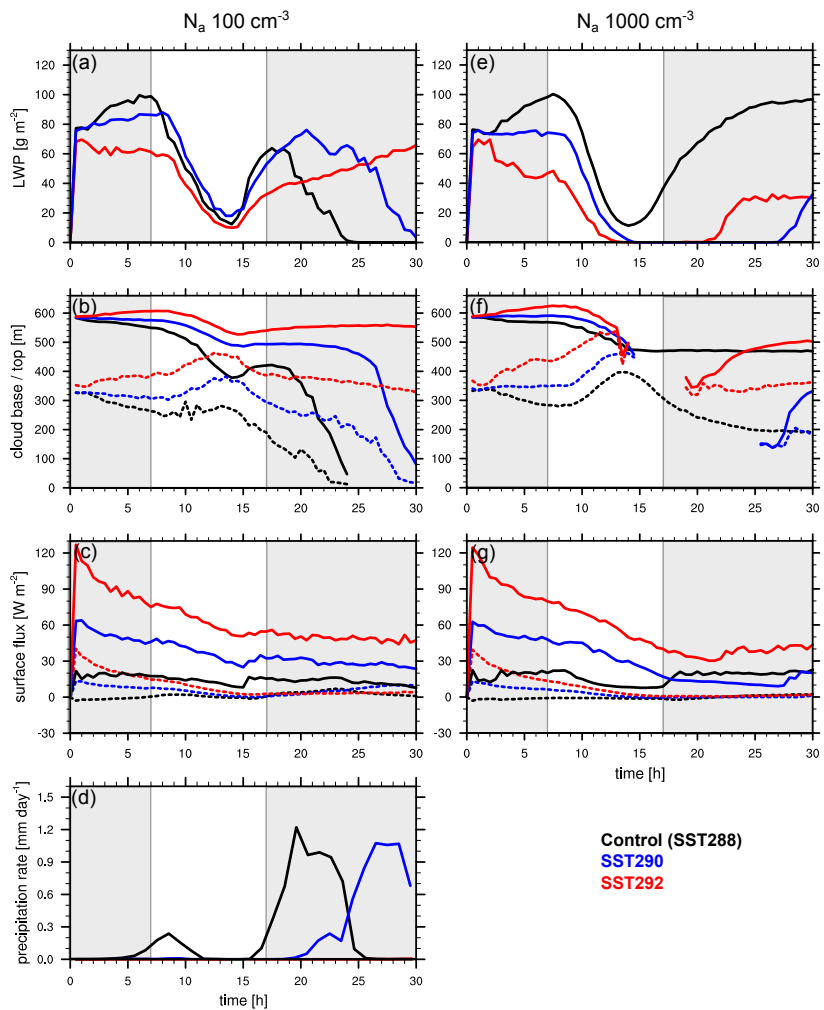

Control (SST288) SST290

Fig. 6. Time evolution of $1 \times 1 \mathrm{~km}^{2}$ clean $\left(N_{\mathrm{a}}=100 \mathrm{~cm}^{-3}\right.$, left column $)$ and polluted $\left(N_{\mathrm{a}}=1000 \mathrm{~cm}^{-3}\right.$, right column $)$ cloud for Control (black), SST290 (blue) and SST292 (red) case: (a) and (e) average LWP; (b) and (f) average cloud top/base height; (c) and (g) domain average surface latent (solid line) and sensible (dashed line) heat flux; (d) surface precipitation rate, hourly averaged.

lower in the polluted condition than in the semi-polluted condition for the $30 \mathrm{~h}$ duration (Fig. 5a). After $15 \mathrm{~h}$, as in the case of the semi-polluted cloud, the well-mixed MBL is restored through enhanced LW cooling and TKE, and the cloud grows even thicker than during the first night. Compared to the clean case, in the absence of precipitation the MSc lifetime increases.

It is shown that when the surface precipitation rate exceeds $\sim 0.1 \mathrm{~mm} \mathrm{day}^{-1}$, the LWP increases with $N_{\mathrm{d}}$ (following effect (b)). Similar trends have also been found in other nocturnal MSc studies (Table 1), in which opposite responses of LWP to an increase in $N_{\mathrm{a}}$ for moderate/heavy and non/light drizzling conditions occur. In Fig. 5f, the cloud optical depth, $\tau$, is calculated by

$\tau=\iint 2 \pi r^{2} n(r) d r d z$

where the extinction efficiency is approximately 2 at visible wavelengths for the typical size of cloud drops (Seinfeld and Pandis, 2006), and $n(r)$ is the droplet number concentration distribution. It is shown that the cloud optical depth increases with $N_{\mathrm{a}}$ (Fig. 5f), with larger enhancement at night than during the daytime. During the $30 \mathrm{~h}$ simulation, cloud optical depth, as well as LWP, precipitation, and cloud fraction exhibit a strong diurnal variation (Fig. 5). The cloud fraction remains $100 \%$ for semi-polluted and polluted cases except from 12 to $14 \mathrm{~h}$ when SW heating is strongest. However, under clean condition, with both precipitation and solar heating, cloud fraction decreases significantly (Fig. 5g). Also, as a result of more pronounced entrainment, the polluted cloud is warmer and drier than the clean and semi-polluted clouds (Fig. 4b, c).

The overall effect (Control cases) of changes in $N_{\mathrm{a}}$ can be summarized as follows: (1) with non/light drizzle (surface precipitation rate $<0.1 \mathrm{~mm} \mathrm{day}^{-1}$ ), increase in $N_{\mathrm{a}}$ results in stronger entrainment and thus lower LWP; and (2) with moderate/heavy drizzle (surface precipitation rate $>0.1 \mathrm{~mm} \mathrm{day}^{-1}$ ), increase in $N_{\mathrm{a}}$ results in precipitation suppression, and thus higher LWP. (Note that clouds are classified as non/light drizzling and moderate/heavy drizzling rather than as clean and polluted.) For the diurnal variation, nighttime LWP is larger than daytime LWP, a result of cloud thinning and decoupling during daytime. Overall, cloud optical depth $\tau$ increases with increased $N_{\mathrm{a}}$ (Fig. 5f). These effects are consistent with the studies listed in Table 1.

\subsection{Sensitivity to environmental conditions}

\subsubsection{Effects of SST - SST290 and SST292 cases}

First, we examine the effect of a higher SST on the response of the MSc to perturbations in aerosol concentration. As SST increases, the surface sensible and latent heat fluxes increase accordingly (Fig. 6c, g), resulting in higher $\theta_{l}$ and $q_{t}$ in the MBL (Fig. 7b, c). The extent of heating exceeds the extent of moistening in terms of affecting the relative humidity, resulting in lower relative humidity under higher SST, and thus higher cloud base. The increased surface fluxes also enhance the TKE (Fig. 7a) and cloud top entrainment, and therefore deepen the cloud by rising cloud top (Fig. 6b). Overall, cloud base rises more than cloud top, resulting in a thinner cloud, consistent with the short time scale responses in Lu and Seinfeld (2005). In SST290 and SST292 clean cases, the precipitation is suppressed (Fig. 6d) because of a thinner cloud and lower LWP. During the daytime, the cloud thickness is constrained by both solar absorption and the warmer MBL. In the second night, the LW radiation enhances the turbulence and MBL overturning, and a well-mixed state is reestablished, causing the cloud to thicken. The precipitation in SST290 clean case initiates at $\sim 20 \mathrm{~h}$, and with moderate drizzling rate $\left(0.1-1 \mathrm{~mm} \mathrm{day}^{-1}\right)$ after $21 \mathrm{~h}$, the cloud becomes very thin in the end of simulation. While in SST292 clean case, lower LWP prevents the cloud from drizzling, and it keeps thickening in the second night.

In SST290 and SST292 polluted cases, stronger entrainment drying/warming due to evaporation and sedimentation 

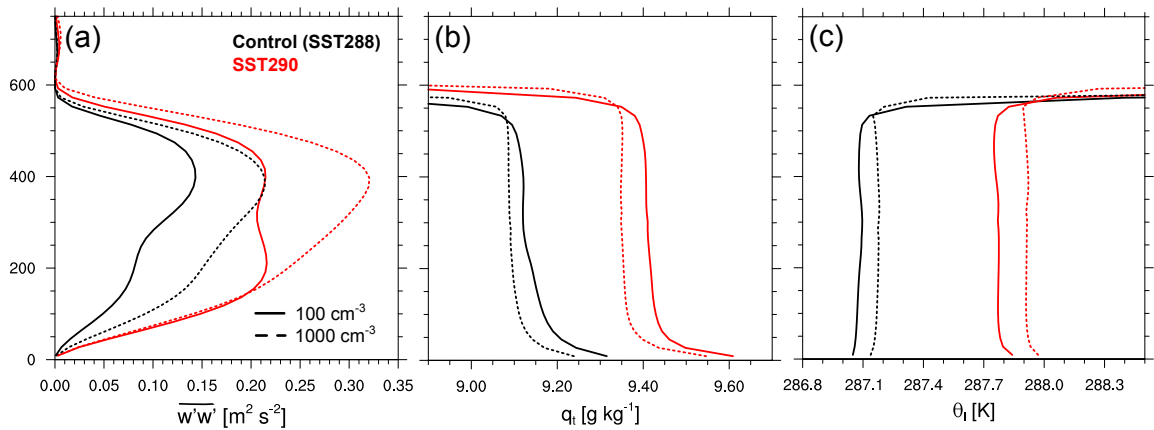

Fig. 7. Vertical profile averaged over 4-6h of (a) mean vertical velocity variance, (b) mean total water mixing ratio $q_{t}$, and (c) mean liquid water potential temperature $\theta_{l}$ for Control (black)/SST290 (red) and clean (solid line)/polluted (dashed line) case.

feedbacks as compared to that in clean cases further dries the MBL, leading to cloud dissipation at $\sim 14 \mathrm{~h}$ with existence of strong solar heating. With the onset of the second night, the LW-driven TKE enhances the vertical advection of water vapor, gradually replenishing moisture at the lifting condensation level. The cloud reforms at $\sim 27 \mathrm{~h}$ and $20 \mathrm{~h}$ for SST290 and SST292 polluted cases, respectively (Fig. 6f).

The overall effect of an increasing SST can be summarized as follows: (1) when SST is increased as compared to the Control case, the simulated cloud thins and LWP decreases on a short time scale (several hours); and (2) when SST is increased and $N_{\mathrm{a}}$ is increased, entrainment effects are more pronounced and LWP decreases.

\subsubsection{Effects of free tropospheric humidity - QFT3 and QFT1 cases}

As the free tropospheric air becomes drier, the larger discontinuity in humidity between the MBL and the free troposphere results in stronger evaporative cooling in the cloud top inversion region. This enhances the TKE and leads to stronger mixing and increased cloud top entrainment. As more dry air is entrained into the cloud layer, the MBL gets drier, causing the surface latent heat flux to increase. Compared to the Control case, the enhanced cloud top entrainment leads to a deeper MBL as well as stronger drying and warming. As a result, both the cloud top and base rise (Fig. 8b, f), with the cloud base rising more, thus resulting in a thinner cloud. The effects of the free tropospheric moisture can be summarized (Ackerman et al., 2004) as: (1) moist entrained air $\rightarrow$ does not dry MBL effectively $\rightarrow$ cloud thickening, versus (2) dry entrained air $\rightarrow$ dry the MBL $\rightarrow$ cloud thinning. Similar results were also obtained by Sandu et al. (2008) for a diurnal cycle.

In the QFT3 case, no precipitation indicates stronger mixing in the MBL so the vapor from the surface is transported more efficiently to the cloud layer. The increased surface moisture flux compensates for the drying from enhanced entrainment, and the cloud thickens at night. However in the
QFT1 case, the cloud thins as drying from entrainment mixing exceeds the moistening from the surface flux (Fig. 8a, e). In the QFT3 clean case, the precipitation occurs after $20 \mathrm{~h}$, with heavier drizzle $\left(>0.1 \mathrm{~mm} \mathrm{day}^{-1}\right)$ occurring after $21 \mathrm{~h}$. The cloud eventually dissipates by the end of simulation. On the other hand, the lower LWP in the QFT1 clean case prevents the cloud from precipitating during the $30 \mathrm{~h}$ duration. In the second night, the cloud deepens as the surface moisture flux outweighs the drying by entrainment, and LWP gradually increases. Compared to the QFT1 polluted case, LWP is higher in the clean case than in the polluted case within the $30 \mathrm{~h}$ duration.

The overall effect of a drier free troposphere can be summarized as follows: (1) when $q_{\mathrm{ft}}$ is decreased as compared to the Control case, the cloud thins and LWP decreases on a short time scale; and (2) when $q_{\mathrm{ft}}$ is decreased and $N_{\mathrm{a}}$ is increased, entrainment effects are significant and LWP decreases.

\subsubsection{Effects of large-scale divergence - DIV3 and DIV8 Cases}

Changes in the large-scale divergence rate mainly affect the cloud top height. As the large-scale divergence weakens (DIV3), the cloud height increases, and the cloud thickens. In the DIV3 clean case, this results in earlier and heavier precipitation than in the Control case (Fig. 9d). During the first night, surface precipitation initiates at $\sim 4 \mathrm{~h}$ with a maximum rate of $0.45 \mathrm{~mm} \mathrm{day}^{-1}$. During the day, LWP decreases, reaching a minimum at $\sim 14 \mathrm{~h}$ (Fig. 9a), the same as in the Control case. The cloud thickens again afterwards as the SW heating decreases. Due to the lower cloud layer in the second evening (Fig. 9b), precipitation droplets are less likely to evaporate before reaching the surface, causing heavier surface precipitation to occur between 16 and $21 \mathrm{~h}$, with a maximum rate of $1.2 \mathrm{~mm} \mathrm{day}^{-1}$, and eventually the cloud dissipates at $\sim 22 \mathrm{~h}$.

In the DIV3 polluted case, the cloud thickens with the LWP reaching $\sim 150 \mathrm{gm}^{-2}$ during the first night, as 

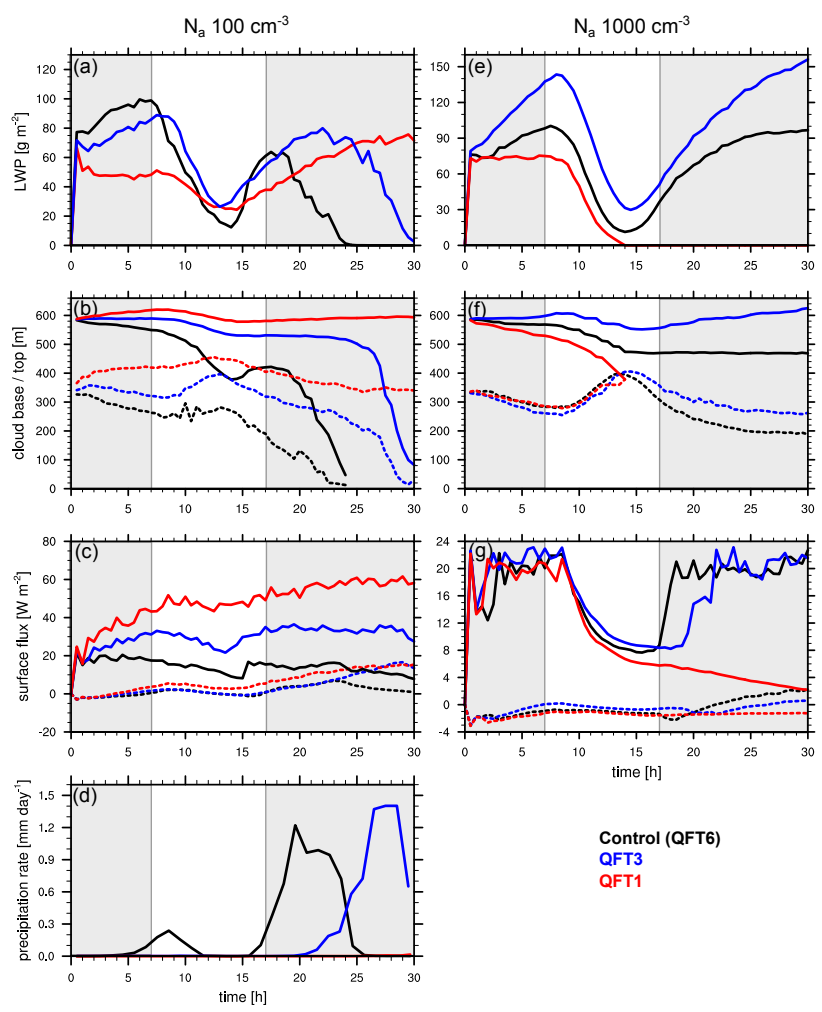

Control (QFT6)

QFT3
QFT1

Fig. 8. The same as Fig. 6, except for Control (black), QFT3 (blue) and QFT1 (red) case.

compared to $\sim 100 \mathrm{gm}^{-2}$ in the Control case (Fig. 9e). During the second night, the cloud grows even thicker, with LWP reaching $160 \mathrm{gm}^{-2}$ at the end of the simulation, showing that with a weaker subsidence rate, the polluted cloud can keep thickening without being strongly capped.

In the DIV8 case, on the other hand, the stronger subsidence results in a lower inversion height and therefore a lower cloud top height. In the DIV8 clean case, lower LWP inhibits precipitation during the first night. Compared to the DIV3 and Control clean clouds, the cloud dissipates later due to later onset and less drizzle. In the DIV8 polluted case, however, the cloud disappears due to stronger subsidence and daytime solar absorption. It is shown that when the subsidence rate is increased, the cloud thins due to a decrease in cloud top height and is even able to dissipate completely. The overall effect of the large-scale divergence rate can be summarized as follows: (1) in the precipitating case, when $D$ is increased as compared to the Control case, the cloud thins and LWP decreases on a short time scale; and (2) when $D$ is increased (decreased) and $N_{\mathrm{a}}$ is increased, stronger entrainment (precipitation suppression) leads to lower (higher) LWP.
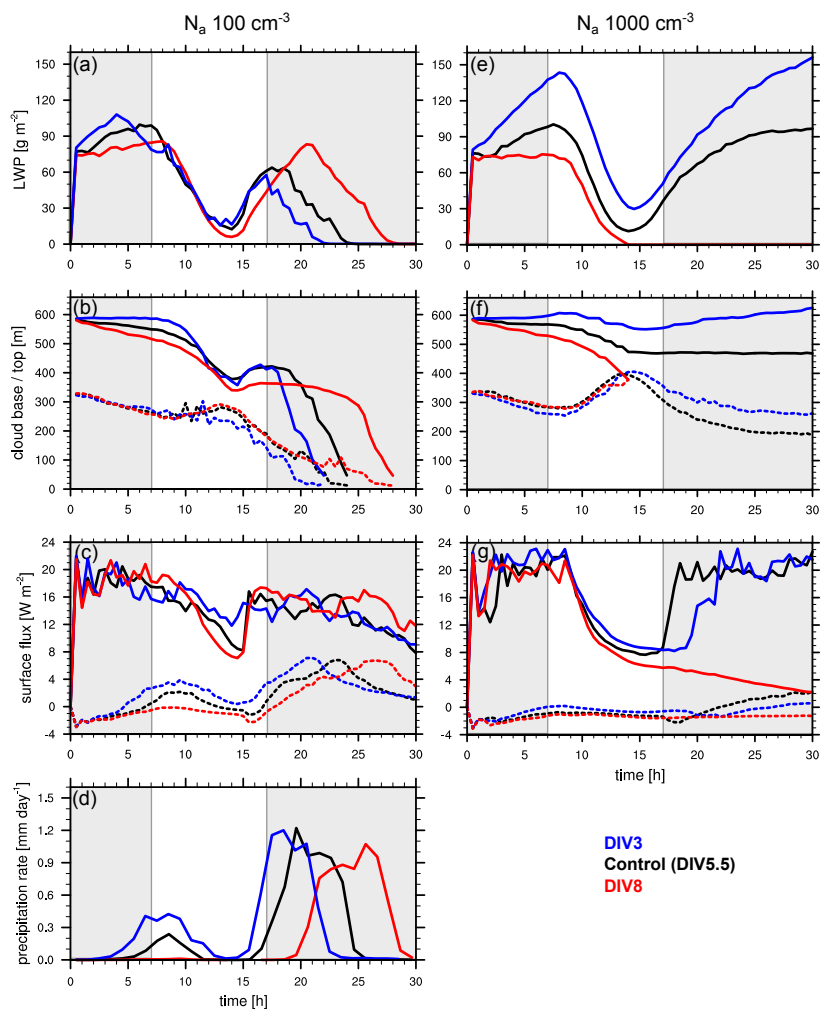

DIV3

Control (DIV5.5)

DIV8

Fig. 9. The same as Fig. 6, except for Control (black), DIV3 (blue) and DIV8 (red) case.

\subsubsection{Effects of wind speed - WIND Cases}

Stronger wind ( $U$ and $V$ are -4 and $10 \mathrm{~ms}^{-1}$, respectively; compared to -1 and $6 \mathrm{~ms}^{-1}$ in Control case) increases the surface latent heat fluxes, resulting in slightly higher LWP than in the Control case, and thus more precipitation in the clean case (Fig. 10d). Stronger sedimentation lowers the cloud top and base relative to the Control case (Fig. 10b). In the afternoon, the LWP increases and heavy drizzle occurring in the clean case causes the cloud to disappear at $\sim 21 \mathrm{~h}$, earlier than that in the Control clean case. This is a result of significant water loss due to low cloud base. In the polluted case, on the other hand, it shows similar diurnal variation as the Control case (Fig. 10f), but with higher LWP than the Control case at night. It is shown that within the range simulated, the cloud response is not very sensitive to the wind speed compared to other environmental variables.

The overall effect of stronger wind speed can be summarized as follows: (1) when $U, V$ are increased as compared to the Control case, the cloud thickens and LWP increases, resulting in heavier precipitation (short time scale); and (2) when $U, V$ are increased and $N_{\mathrm{a}}$ is increased, precipitation is suppressed and LWP is higher than that of the case with lower $N_{\mathrm{a}}$. 

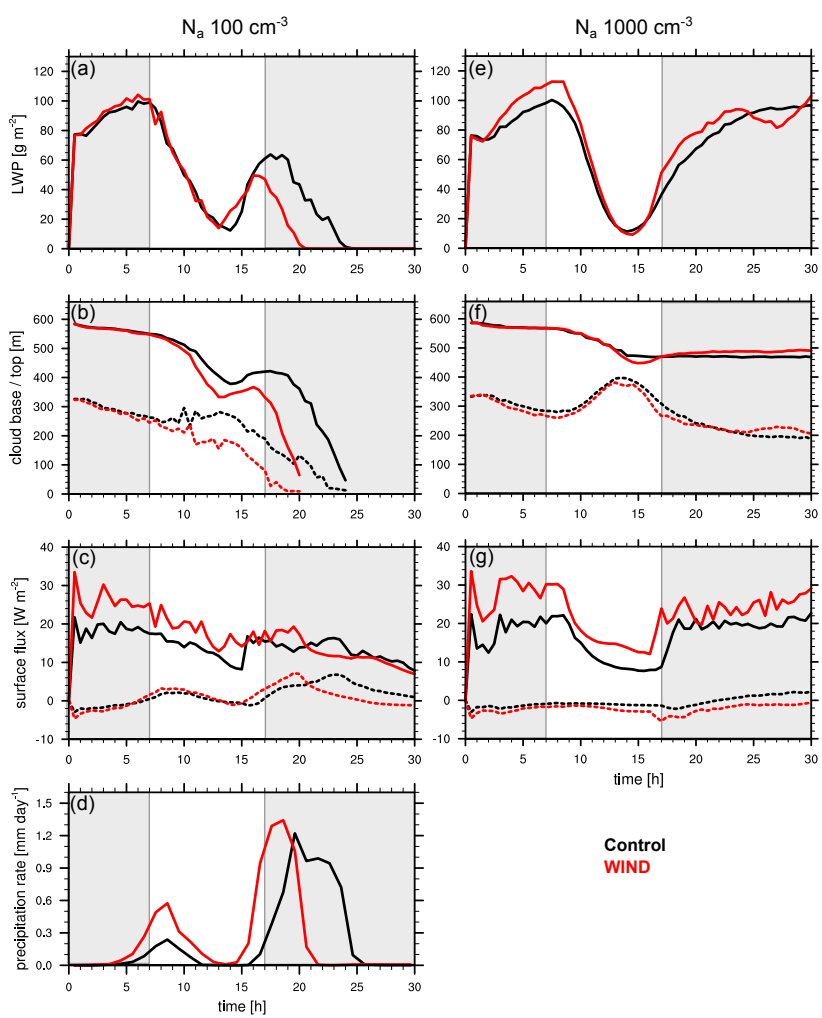

Control

Fig. 10. The same as Fig. 6, except for Control (black) and WIND (red) case.

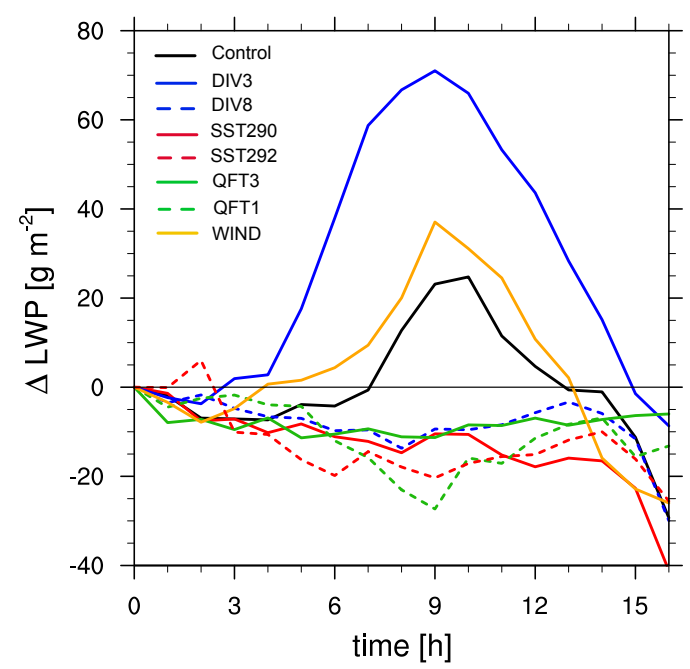

Fig. 11. Time evolution of LWP difference between polluted and clean condition for Control (black), SST290 (red solid), SST292 (red dashed), QFT3 (green solid), QFT1 (green dashed), DIV3 (blue solid), DIV8 (blue dashes), and WIND (orange) case.

\subsection{LWP differences between clean and polluted cases}

The LWP difference between the polluted and clean case ( $\triangle \mathrm{LWP}$ ) for all cases is shown in Fig. 11 (after $16 \mathrm{~h}$ the cloud dissipates in some cases). For Control, DIV3 and WIND cases, LWP is higher under polluted conditions $(\triangle \mathrm{LWP}>0)$, with the maximum $\Delta$ LWP reaching $70 \mathrm{gm}^{-2}$ in the DIV3 case. This is because under these conditions in which heavier precipitation occurs (Figs. 9d, 10d), the increase in aerosol number concentration more effectively suppresses precipitation, resulting in less water loss and higher LWP. In contrast, the other cases (SST290, SST292, DIV8, QFT3 and QFT1 case) have lower LWP in the polluted condition than the clean condition $(\Delta \mathrm{LWP}<0)$, which shows that in the absence of precipitation or with light drizzle, the evaporationentrainment effect and sedimentation-entrainment effect are pronounced in the polluted case, causing LWP to decrease. The minimum $\Delta$ LWP is $\sim-28 \mathrm{gm}^{-2}$ in the QFT1 case, showing that the drier the free troposphere, the stronger the entrainment effect. The time evolution of difference in LWP between polluted and clean condition has the same tendency as compared to Fig. 7 of Sandu et al. (2008), with larger LWP difference under moister conditions, and vice versa. Also, during daytime the LWP difference decreases, and becomes negative for all simulations after $\sim 14 \mathrm{~h}$, similar to the results in Sandu et al. (2008).

\subsection{Relation of LES experiments to analytical approximation}

Equation (3) is an approximate analytical expression relating changes in $N_{\mathrm{a}}$ to changes in various cloud properties. Here we attempt to estimate the sign and relative magnitude of each term in Eq. (3) using the LES experiments. To evaluate the derivatives we use finite differences, $\Delta N_{\mathrm{a}}$, to represent $d N_{\mathrm{a}}$, using $N_{\mathrm{a}}$ values of $100,200,500$ and $1000 \mathrm{~cm}^{-3}$. As noted earlier, while the adiabaticity effect, $d(\ln f) / d\left(\ln N_{\mathrm{a}}\right)$, is expressed separately in Eq. (3), this effect cannot easily be separated numerically from the others in Eq. (3). Therefore, $\Delta \ln N_{\mathrm{d}} / \Delta \ln N_{\mathrm{a}}$ is estimated rather than $\Delta \ln N_{\mathrm{ad}} / \Delta \ln N_{\mathrm{a}}$; and the estimation of $\Delta \ln k / \Delta \ln N_{\mathrm{a}}$ and $\Delta \ln H / \Delta \ln N_{\mathrm{a}}$ already incorporates the adiabaticity effect. Control, SST290, QFT3, and DIV3 cases are considered to evaluate each term. The relationship of $\tau, N_{\mathrm{d}}, k$, and $H$ to $N_{\mathrm{a}}$ are calculated by conditionally-averaging over the cloudy fraction of the domain. Nighttime (4-7 h) and daytime (12-15 h) are discussed separately (Fig. 12).

\subsubsection{Twomey effect}

The estimated value of $\Delta \ln N_{\mathrm{d}} / \Delta \ln N_{\mathrm{a}}$ is within the range of $1.00-1.25$ at night $(4-7 \mathrm{~h}$ ) and $0.83-1.37$ during the day (12$15 \mathrm{~h}$ ) (Table 4), with lower values in SST290 and QFT3 cases than in Control and DIV3 cases, a result of lower relative humidity and lower supersaturation, and thus lower $N_{\mathrm{d}}$. During 

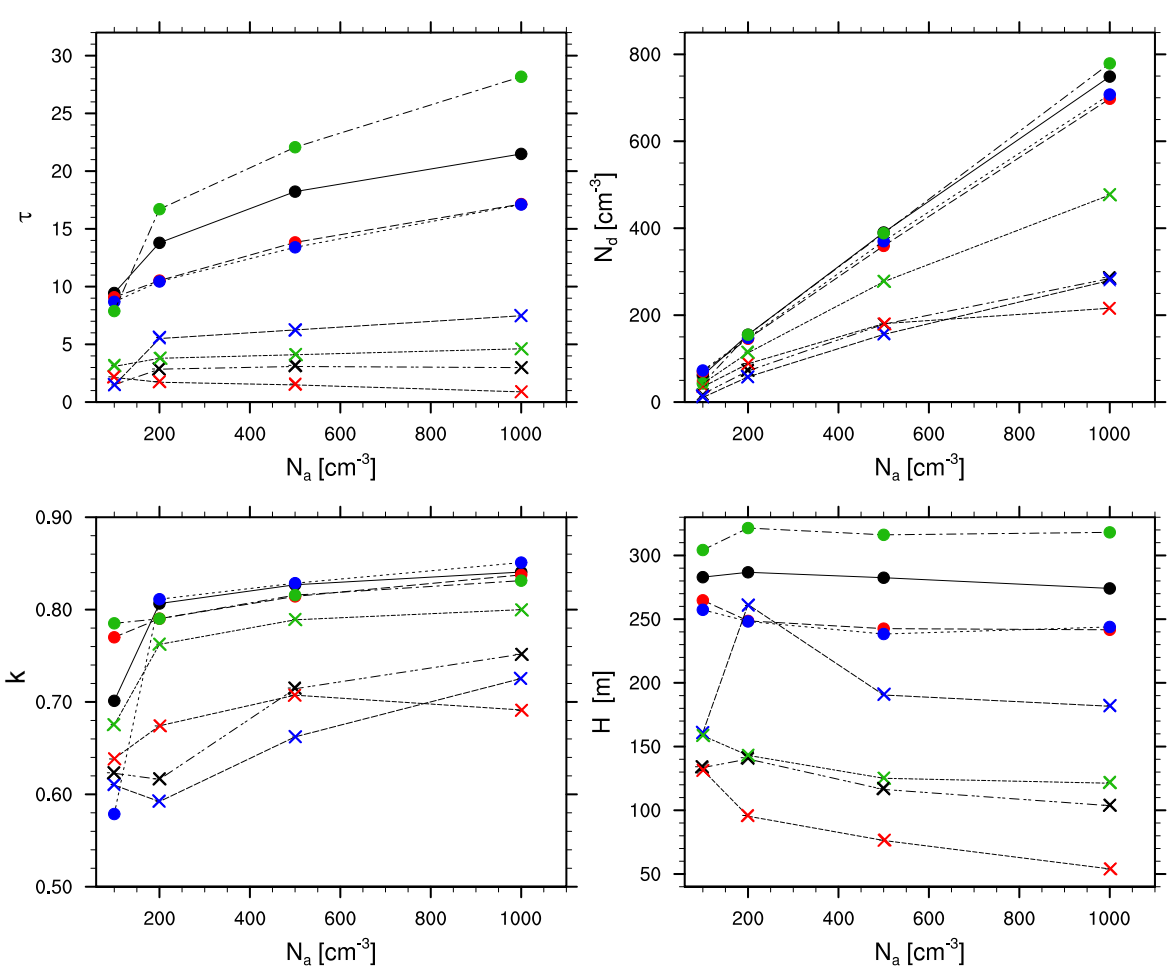

Fig. 12. Averaged optical depth $(\tau)$, cloud droplet number concentration $\left(N_{\mathrm{d}}\right)$, dispersion coefficient $(k)$ and cloud thickness $(H)$ as a function of aerosol number concentration $N_{\mathrm{a}}$. Values are averaged horizontally and vertically between cloud top and base for Control (black), SST290 (red), QFT3 (blue), and DIV3 (green) cases during nighttime (averaged over 4-7 h, filled circle) and daytime (average over 12-15 h, cross).

the daytime, $N_{\mathrm{d}}$ is lower than that at nighttime due to solar heating (Fig. 12), and the values of $\Delta \ln N_{\mathrm{d}} / \Delta \ln N_{\mathrm{a}}$ are more scattered. Compared to other studies (Table 2), the estimated magnitude of $\Delta \ln N_{\mathrm{d}} / \Delta \ln N_{\mathrm{a}}$ is higher, as compared to the range of 0.6 to 0.9 based on Eqs. (4) and (5).

\subsubsection{Dispersion effect}

The coefficient $k$ is calculated (Martin et al., 1994; Lu and Seinfeld, 2006) as a function of relative dispersion $(d)$ and skewness $(s)$ of the droplet number concentration distribution $n(r)$,

$k=\frac{\left(1+d^{2}\right)^{3}}{\left(s d^{3}+1+3 d^{2}\right)^{2}}$,

where $d=\sigma / \bar{r}, \bar{r}$ is mean droplet radius, $\sigma$ is the standard deviation of droplet spectrum, given by

$\sigma=\left(\frac{1}{N_{\mathrm{d}}} \int(r-\bar{r})^{2} n(r) d r\right)^{1 / 2}$,

and skewness $s$ is defined as

$s=\frac{1}{\sigma^{3} N_{\mathrm{d}}} \int(r-\bar{r})^{2} n(r) d r$.
Calculated over the cloud and drizzle spectra, the range of $k$ from the simulations is within 0.58 and 0.85 (Fig. 12). During the daytime, $k$ is smaller than at night, suggesting that the evaporation of cloud droplets due to SW heating results in a more dispersed droplet spectrum and smaller $k$. Also, the estimated $\Delta \ln k / \Delta \ln N_{\mathrm{a}}$ at nighttime is smaller for the drier cases (SST290 and QFT3), and larger for the moister case (DIV3). In the DIV3 case with stronger precipitation, $\Delta \ln k / \Delta \ln N_{\mathrm{a}}$ accounts for $10 \%$ of total cloud susceptibility, larger than in other cases with less precipitation; this result is consistent with Lu and Seinfeld (2006), where smaller value of $\Delta \ln k / \Delta \ln N_{\mathrm{a}}$ occurs for the cloud with weaker drizzle, and larger value with stronger precipitation. This is because with increased $N_{\mathrm{a}}$, there is less spectral broadening due to suppressed collision-coalescence. Also, suppressed precipitation leads to stronger TKE and higher updraft velocities, resulting in spectral narrowing via condensational growth in regions of higher updraft velocities. The positive correlation of $k$ to $N_{\mathrm{a}}$ is consistent with Miles et al. (2000) and individual ship tracks in Lu et al. (2007), yet opposite to that obtained by other flight-averaged data (Martin et al.; 1994; Liu and Daum; 2002; ensemble cloud averages in Lu et al., 2007).

Lu et al. (2007) found that on the ensemble-averaged cloud scale ( $\sim$ several tens of kilometers), an increase in $N_{\mathrm{a}}$ results in spectral broadening (smaller $k$ ), because for the flight- 
averaged data, the relationship between $k$ and $N_{\mathrm{a}}$ is affected not only by $N_{\mathrm{a}}$ but also by various meteorological conditions in different sampling locations. The meteorological differences thus affect the dynamical factors, such as entrainment mixing, updraft velocity, drizzle strength, etc, which accordingly change the dispersion width. Therefore for the flightaveraged observational data, the clean and polluted cases were not necessarily subject to the same sounding ( $\mathrm{Lu}$ et al., 2007), which causes the $k-N_{\mathrm{a}}$ relationship to be affected by factors other than simply changes in $N_{\mathrm{a}}$. While on the scale of a cloud perturbed by a single ship track, spectral narrowing (larger $k$ ) occurs in response to increased $N_{\mathrm{a}}$, for which the ship track and clean regions are embedded in the same sounding. In this LES study, with the ambient conditions being fixed, the environment is identical, and the aerosolinduced dispersion changes can therefore be distinguished and separated from other meteorological factors.

\subsubsection{Cloud thickness effect}

Aerosols exert the main influence on cloud thickness through precipitation efficiency, radiation, and cloud dynamics (entrainment). The estimated $\Delta \ln H / \Delta \ln N_{\mathrm{a}}$ at nighttime is slightly negative ( $\sim 0.01$ to -0.04$)$ within the range of simulated environmental conditions (Table 4), except for the DIV3 case $\left(\Delta \ln H / \Delta \ln N_{\mathrm{a}}=0.014\right)$ in which stronger drizzle occurs in the clean case, causing $H$ to increase with increasing $N_{\mathrm{a}}$, a result of precipitation suppression. As $N_{\mathrm{a}}$ increases from 200 to $1000 \mathrm{~cm}^{-3}, \Delta \ln H / \Delta \ln N_{\mathrm{a}}$ is negative in all cases (Fig 12) as a result of evaporation-entrainment and sedimentation-entrainment effects. During the daytime, $H$ is smaller and the values of $\Delta \ln H / \Delta \ln N_{\mathrm{a}}$ is more scattered than at night. The sign of $\Delta \ln H / \Delta \ln N_{\mathrm{a}}$ is consistent with $\mathrm{Lu}$ and Seinfeld (2005) (Table 2), where $\partial \ln L W P / \partial \ln N_{\mathrm{a}}$ is negative, with a larger impact under clean background. The cloud thickness effect is the only one that exhibits either positive or negative magnitude, which enhances or counteracts other effects.

\subsubsection{Cloud optical depth susceptibility}

Cloud optical depth is calculated following Eq. (7). As $N_{\mathrm{a}}$ increases from 100 to $1000 \mathrm{~cm}^{-3}$, the estimated value of $\Delta \ln \tau / \Delta \ln N_{\mathrm{a}}$ lies between 0.28 and 0.53 at night, with higher value in the DIV3 case and lower value in the SST290 and QFT3 cases (Table 4). This suggests that with a moister atmosphere and heavier precipitation, $\Delta \ln \tau / \Delta \ln N_{\mathrm{a}}$ is larger. Also, $\Delta \ln \tau / \Delta \ln N_{\mathrm{a}}$ is larger at lower $N_{\mathrm{a}}$. In the nighttime Control case, as $N_{\mathrm{a}}$ doubles from 100 to $200 \mathrm{~cm}^{-3}$, $\Delta \ln \tau / \Delta \ln N_{\mathrm{a}}$ is more than two times larger than that when doubling $N_{\mathrm{a}}$ from 500 to $1000 \mathrm{~cm}^{-3}$ (0.54 versus 0.24$)$, suggesting that total cloud susceptibility is stronger under lower $N_{\mathrm{a}}$. This is because when $N_{\mathrm{a}}$ increases from that of a clean background, transition from precipitating to non-

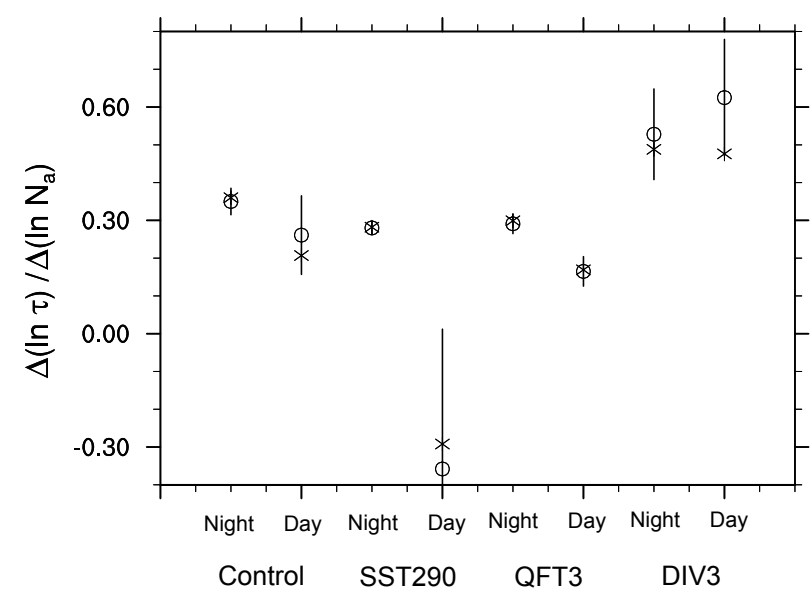

Fig. 13. Averaged $\Delta(\ln \tau) / \Delta\left(\ln N_{\mathrm{a}}\right)$ from the LES model (unfilled circle) and Eq. (3) (asterisk) for specific sensitivity simulations under nighttime (4-7 h) and daytime (12-15 h), as shown in last two columns of Table 4. The error bar (standard deviation) is computed from LES experiments.

precipitating cloud results in more pronounced enhancement of total cloud susceptibility.

During the daytime, the magnitude of $\tau$ is lower as a result of solar heating and cloud thinning (Fig. 12). The magnitude of $\Delta \ln \tau / \Delta \ln N_{\mathrm{a}}$ lies between -0.36 and 0.63 , more scattered than that of the nighttime (0.28-0.53). Because the MBL decouples and the cloud thins significantly during the day, the evaluation which is based on only cloudy grids has a larger standard deviation and should be viewed with more caution. In the SST290 case, $\Delta \ln \tau / \Delta \ln N_{\mathrm{a}}$ is actually negative during the day, a result of cloud dissipation under polluted case. With higher temperature, cloud droplet evaporation during the day causes the cloud to disappear (Fig. 6f).

Comparing $\Delta \ln \tau / \Delta \ln N_{\mathrm{a}}$ from LES simulation (Eq. 7) and from Eq. (3), it is seen that the two values are in good agreement to each other (Fig. 13). The difference between these two estimated $\Delta \ln \tau / \Delta \ln N_{\mathrm{a}}$ value lies within the margin of error (standard deviation), with greater discrepancy occurring in daytime SST290 case. Note that the standard deviation is larger for daytime SST290, showing the value is less representative than in other cases. The relatively close agreement between the LES simulation and analytical expression in Eq. (3) was not necessarily to be expected. The analytical formulation can therefore be treated as a good approximation of cloud optical depth susceptibility.

Considering the significance of each term in contributing to the cloud susceptibility $\Delta \ln \tau / \Delta \ln N_{\mathrm{a}}$, the Twomey effect $\Delta \ln N_{\mathrm{d}} / \Delta \ln N_{\mathrm{a}}$ is the dominant term, contributing over $85 \%$ of the total effect during the nighttime. The dispersion effect accounts for $3 \%$ to $10 \%$ of the total effect at night, and the cloud thickness effect accounts for $5 \%$ to $22 \%$ of the overall effect, acting to diminish or enhance the Twomey effect. 
Table 4. Estimation of aerosol-induced effects on MSc cloud properties from the LES model and of cloud susceptibility from Eq. (3) for specific sensitivity simulations under nighttime (4-7 h) and daytime (12-15 h) conditions; aerosol number concentrations considered are 100, 200,500 , and $1000 \mathrm{~cm}^{-3}$.

\begin{tabular}{|c|c|c|c|c|c|c|c|c|c|c|c|}
\hline & & \multicolumn{2}{|c|}{$\frac{\Delta\left(\ln N_{\mathrm{d}}\right)}{\Delta\left(\ln N_{\mathrm{a}}\right)}$} & \multicolumn{2}{|c|}{$\frac{\Delta(\ln k)}{\Delta\left(\ln N_{\mathrm{a}}\right)}$} & \multicolumn{2}{|c|}{$\frac{\Delta(\ln H)}{\Delta\left(\ln N_{\mathrm{a}}\right)}$} & \multicolumn{2}{|c|}{$\frac{\Delta(\ln \tau)}{\Delta\left(\ln N_{\mathrm{a}}\right)}$} & \multicolumn{2}{|c|}{$\frac{\Delta(\ln \tau)}{\Delta\left(\ln N_{\mathrm{a}}\right)}($ Eq. 3) } \\
\hline & & Night & Day & Night & Day & Night & Day & Night & Day & Night & Day \\
\hline \multirow[t]{2}{*}{ Control } & Mean & 1.077 & 1.158 & 0.072 & 0.094 & -0.014 & -0.126 & 0.350 & 0.261 & 0.360 & 0.207 \\
\hline & Stdev & 0.049 & 0.029 & 0.016 & 0.030 & 0.010 & 0.034 & 0.035 & 0.104 & & \\
\hline \multirow[t]{2}{*}{ SST290 } & Mean & 1.000 & 0.805 & 0.036 & 0.050 & -0.038 & -0.346 & 0.280 & -0.358 & 0.282 & -0.292 \\
\hline & Stdev & 0.023 & 0.086 & 0.010 & 0.023 & 0.007 & 0.160 & 0.018 & 0.370 & & \\
\hline \multirow[t]{2}{*}{ QFT3 } & Mean & 1.000 & 1.037 & 0.026 & 0.070 & -0.026 & -0.120 & 0.291 & 0.165 & 0.299 & 0.169 \\
\hline & Stdev & 0.010 & 0.025 & 0.006 & 0.036 & 0.016 & 0.011 & 0.026 & 0.039 & & \\
\hline \multirow[t]{2}{*}{ DIV3 } & Mean & 1.245 & 1.370 & 0.150 & 0.082 & 0.014 & -0.005 & 0.528 & 0.625 & 0.488 & 0.476 \\
\hline & Stdev & 0.128 & 0.070 & 0.047 & 0.018 & 0.013 & 0.050 & 0.120 & 0.154 & & \\
\hline
\end{tabular}

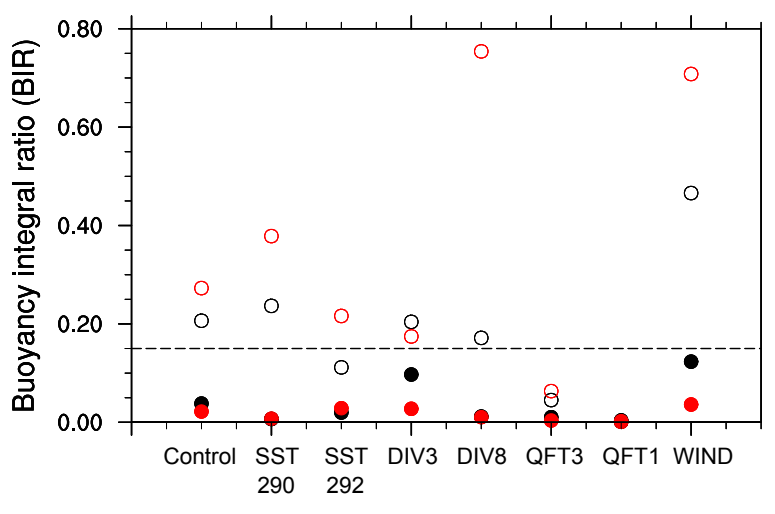

Fig. 14. The buoyancy integral ratio (BIR) for clean $\left(N_{\mathrm{a}}=\right.$ $\left.100 \mathrm{~cm}^{-3}\right)$ nighttime (4-7 h, black), clean daytime $(12-15 \mathrm{~h}$, black open circle), polluted $\left(N_{\mathrm{a}}=1000 \mathrm{~cm}^{-3}\right)$ nighttime (red), and polluted daytime (red open circle) clouds under different environmental conditions. The dashed line corresponds to critical value 0.15 (suggested by Bretherton and Wyant (1997)).

During daytime the ranges of values are more scattered due to the MBL decoupling and significant cloud thinning. Certain processes, including the solar absorption, cloud top entrainment, reducing surface buoyancy fluxes, and drizzle evaporation below cloud base tend to promote a more stable density stratification within the MBL (Nicholls, 1984; Lewellen and Lewellen, 2002). Daytime absorption of solar radiation often leads to afternoon cloud thinning due to decoupling. Decoupling can occur when subcloud buoyancy fluxes become negative, inhibiting convection below cloud base (e.g., Bretherton and Wyant, 1997). The existence of decoupling can be diagnosed using the buoyancy integral ratio (BIR) (Turton and Nicholls, 1987; Bretherton and Wyant, 1997) defined as:

$\mathrm{BIR}=-\int_{z^{*}}\left\langle w^{\prime} \theta_{v}^{\prime}\right\rangle d z / \int_{\text {all other } z}\left\langle w^{\prime} \theta_{v}^{\prime}\right\rangle d z$. where $z^{*}$ indicates integration over the region below cloud base height in which $\left\langle w^{\prime} \theta_{v}^{\prime}\right\rangle<0$, and $\theta_{v}$ is virtual potential temperature. In Turton and Nicholls (1987), the value BIR > 0.4 is chosen as a condition for decoupling of the sub-cloud layer and the cloud layer. Bretherton and Wyant (1997) suggest that the threshold value BIR $>0.15$ is more appropriate. BIR values under nighttime (4-7 h)/daytime (12-15 h) conditions and clean / polluted cases are shown in Fig. 14 for eight cases. If BIR $>0.15$ is used for the decoupling threshold, the MBL in most daytime cases is decoupled. As the daytime solar heating offsets the cloud top radiative cooling, less production of turbulence by cloud-top cooling favors greater decoupling (e.g., Bretherton and Wyant, 1997; Stevens, 2000) and hence a thinning of the stratocumulus layer. The largest BIR is shown in DIV8 polluted case during the daytime condition. In the DIV8 polluted case, stronger subsidence and enhanced entrainment lead to a thinner cloud. Solar heating during the daytime further results in enhanced decoupling of sub-cloud layer and the cloud layer, which leads to cloud dissipation at $\sim 14 \mathrm{~h}$. In the WIND cases, stronger wind helps ventilate the surface. The surface latent heat flux, which is proportional to the mean wind, becomes more negative in the polluted case (Fig. 10g). This results in lower buoyancy flux near the surface, and enhanced decoupling of the sub-cloud layer and cloud layer. Thus BIR is higher under WIND polluted case during the daytime.

Under nighttime conditions, the MBL is well mixed, with BIR $<0.15$ in all cases. However, the MBL under DIV3 and WIND clean conditions has slightly higher BIR than others, indicating that the heavier precipitation in DIV3 and WIND clean conditions leads to a more stable boundary layer and a less mixed/coupled MBL compared to those with lighter or no precipitation. This shows that below-cloud evaporation of drizzle produces a cooler and moister sub-cloud layer that inhibits deep mixing. Overall, it is shown that decoupling is most likely to occur during daytime. 


\subsubsection{Ratio of indirect effects}

Ignoring the dispersion and adiabaticity effects, Eq. (3) can be rewritten as:

$\frac{d \ln \tau}{d \ln N_{\mathrm{a}}}=\frac{1}{3}\left(\frac{d \ln N_{\mathrm{d}}}{d \ln N_{\mathrm{a}}}+5 \frac{d \ln H}{d \ln N_{\mathrm{a}}}\right)$.

One can define the ratios of the cloud thickness effect to the Twomey effect, that is, $R_{\mathrm{IE}}=5\left(\frac{\Delta \ln H}{\Delta \ln N_{\mathrm{d}}}\right)$ (Wood, 2007). A value of $R_{\mathrm{IE}}=1$ corresponds to the cloud thickness effect doubling the Twomey effect, and $R_{\mathrm{IE}}=-1$ implies a complete cancellation the Twomey effect. In Wood (2007), with given environmental forcing, the MLM determines the equilibrium state of the MBL. By perturbing $N_{\mathrm{d}}$ by $5 \%$, the analytical response indicates that $R_{\mathrm{IE}}$ is strongly tied to cloud base height on a short time scale $(0-8 \mathrm{~h})$; and only when the cloud base height is very low does the cloud thickness effect overweigh the Twomey effect.

In this study we perform an examination similar to that of Wood (2007) by doubling the aerosol concentration from 100 to $200 \mathrm{~cm}^{-3}$. Here $R_{\mathrm{IE}}$ is calculated by $5\left(\frac{\Delta \ln H}{\Delta \ln N_{\mathrm{a}}} / \frac{\Delta \ln N_{\mathrm{d}}}{\Delta \ln N_{\mathrm{a}}}\right)$ from the LES simulation, and the value is averaged over 4$7 \mathrm{~h}$ for 27 cases, covering the variables and values listed in Table 5. Fig. 15a demonstrates a similar trend in $R_{\mathrm{IE}}$ as that shown by Wood (2007) (Fig. 8a). With higher cloud base, $R_{\mathrm{IE}}<0$, and vice versa.

The positive $R_{\mathrm{IE}}$ appears only in Control and DIV3 cases, where the moister environment leads to lower cloud base and stronger precipitation in the unperturbed $\left(N_{\mathrm{a}} 100 \mathrm{~cm}^{-3}\right)$ condition. The other cases have negative $R_{\mathrm{IE}}$, suggesting the cloud thickness effect offsets the Twomey effect. In a drier environment, the cloud base is higher, and thus less precipitation occurs under clean conditions. With increased aerosol, the enhanced entrainment effect therefore results in a thinner cloud and negative cloud thickness effect. The lowest $R_{\mathrm{IE}}$ $(-1.47)$ appears under the driest condition (in which SST is $292 \mathrm{~K}, D$ is $8 \times 10^{-6} \mathrm{~s}^{-1}$, and $q_{\mathrm{ft}}$ is $\left.1.1 \mathrm{~g} \mathrm{~kg}^{-1}\right)$. The relationship between $R_{\mathrm{IE}}$ and cloud thickness (Fig. 15b) also shows a positive correlation; a thicker cloud corresponds to a larger $R_{\mathrm{IE}}$, and vice versa.

To fully cover the responses to different aerosol perturbations during nigttime/daytime, $R_{\mathrm{IE}}$ values are also calculated with changes from 100 to $200 \mathrm{~cm}^{-3}$ and 200 to $1000 \mathrm{~cm}^{-3}$ under both nighttime and daytime conditions for four cases (Control, SST290, QFT3, and DIV3, Fig. 16). The same trend of $R_{\mathrm{IE}}$ versus cloud base height is shown as that in Wood (2007), with larger $R_{\mathrm{IE}}$ corresponding to lower cloud base and smaller $R_{\mathrm{IE}}$ corresponding to higher cloud base. The range of $R_{\mathrm{IE}}$ values during the nighttime $(-0.42$ to 0.20$)$ is smaller than that during the daytime ( -4.18 to 1.38 ), showing that $R_{\mathrm{IE}}$ is more scattered during the daytime. From $N_{\mathrm{a}} 100$ to $200 \mathrm{~cm}^{-3}, R_{\mathrm{IE}}$ is positive for both day and night conditions for the heavier drizzling cases (Control and DIV3), and is negative for the non/light drizzling cases (SST290 and QFT3). This suggests that with suppressed pre-
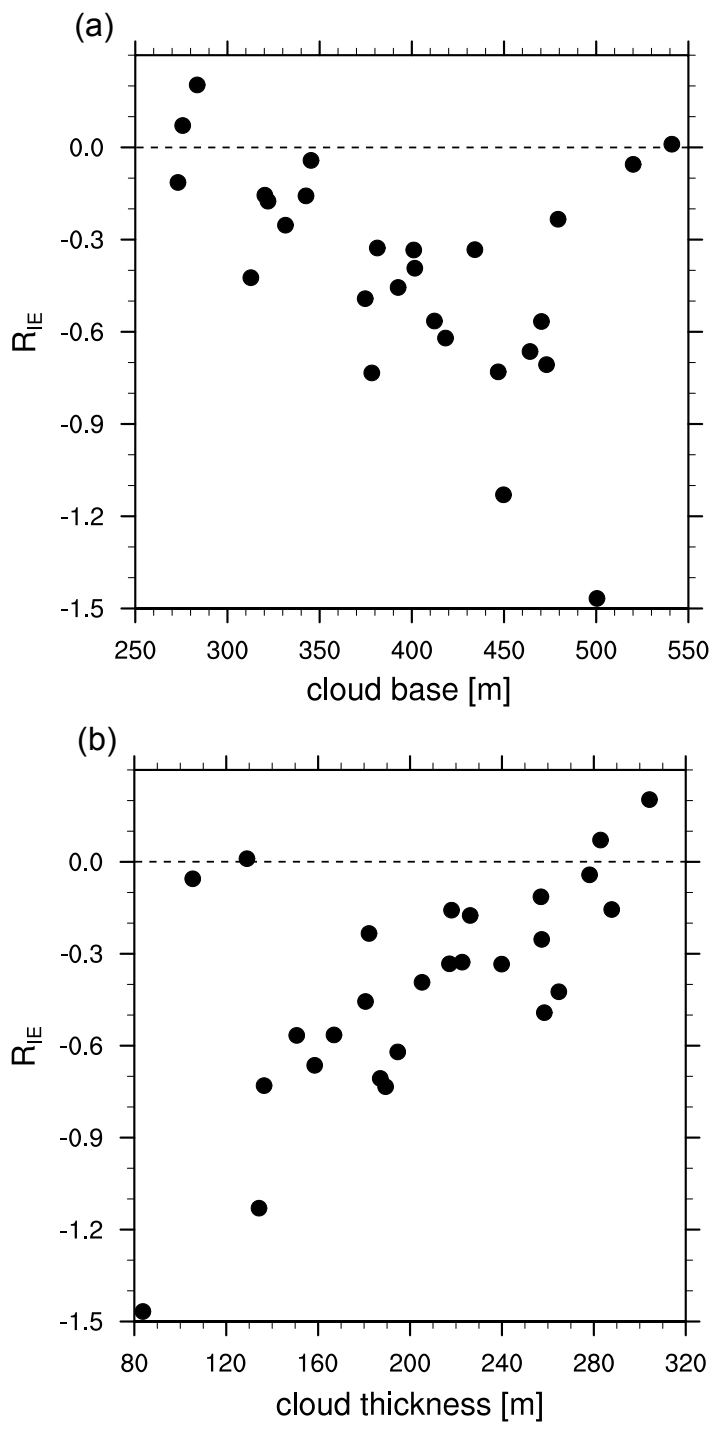

Fig. 15. The mean ratio of second to first indirect effect $\left(R_{\mathrm{IE}}\right)$ for $N_{\mathrm{a}}$ from 100 to $200 \mathrm{~cm}^{-3}$ as a function of (a) cloud base height, and (b) cloud thickness. The data points are averaged over 4-7 h.

cipitation, $R_{\mathrm{IE}}$ tends to be positive (cloud thickens). From $N_{\mathrm{a}} 200$ to $1000 \mathrm{~cm}^{-3}, R_{\mathrm{IE}}$ is negative for all the cases considered, as the pronounced evaporation-entrainment and sedimentation-entrainment feedbacks lead to cloud thinning.

Environmental conditions that favor higher cloud bases are those of higher SST and a drier free troposphere, consistent with results of Wood (2007). Variation in large-scale divergence affects the cloud top height, but not the cloud base height, therefore $R_{\mathrm{IE}}$ under difference divergence rates is independent of cloud base height. 


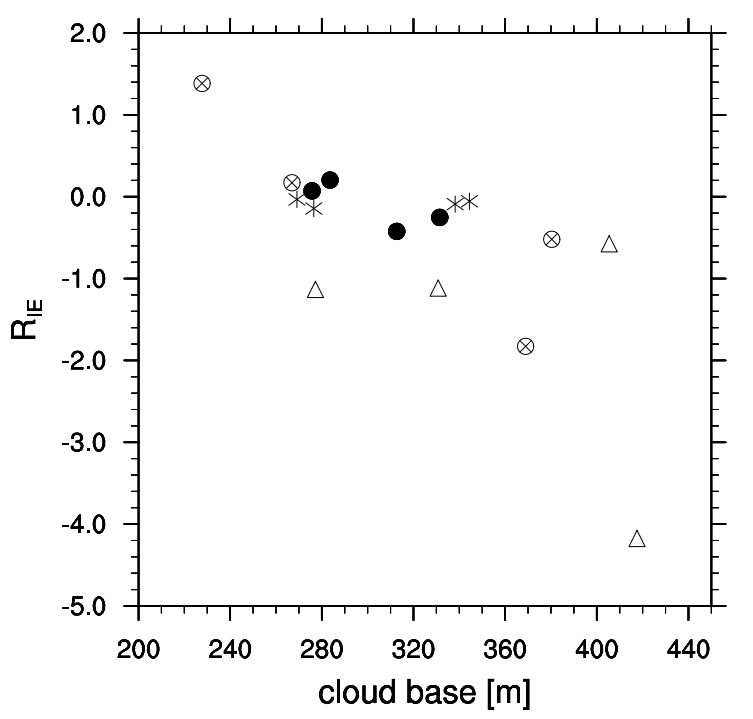

Fig. 16. The mean ratio of second to first indirect effect $\left(R_{\mathrm{IE}}\right)$ for $N_{\mathrm{a}}$ from 100 to $200 \mathrm{~cm}^{-3}$ during nighttime (4-7 h, black filled circle) and daytime (12-15 h, circle with cross inside), and from 200 to $1000 \mathrm{~cm}^{-3}$ during nighttime (asterisk) and daytime (triangle).

\section{Conclusions}

Aerosol-cloud-precipitation interactions, which involve aerosol and cloud microphysics, atmospheric dynamics, and radiation, are complex and intertwined. We report here on a comprehensive numerical study of the dynamical response of MSc to changes in aerosol number concentration $N_{\mathrm{a}}$ using the WRF model with a detailed bin-resolved microphysical scheme as a three-dimensional LES model. Simulations are performed to explore the cloud diurnal responses to varied aerosol number concentration and different meteorological conditions (SST, free-tropospheric water vapor mixing ratio, large-scale subsidence, and wind speed). Based on the LES simulations, the magnitude and sign of the Twomey effect, droplet dispersion effect, cloud thickness effect, and total cloud optical depth susceptibility are evaluated and compared to approximate analytical expressions that have been previously derived.

For moderate/heavy drizzling $\left(>0.1 \mathrm{~mm} \mathrm{day}^{-1}\right.$ ) clouds, increase in $N_{\mathrm{a}}$ suppresses precipitation, causing the LWP to increase. For non/light drizzling $\left(<0.1 \mathrm{~mm} \mathrm{day}^{-1}\right)$ clouds, an increase in $N_{\mathrm{a}}$ leads to numerous smaller cloud droplets, reducing the sedimentation, increasing the evaporation at cloud top, resulting in larger TKE, stronger entrainment, and LWP reduction. These are termed as sedimentationentrainment and evaporation-entrainment effects. In daytime, for the Control case, SW heating partially offsets the LW cooling and thins clouds; and the reduced turbulent mixing results in a decoupled MBL. Over the $30 \mathrm{~h}$ duration, the precipitating cloud under clean background disappears due
Table 5. Values of environmental variables.

\begin{tabular}{ll}
\hline \multicolumn{1}{c}{ Variable } & \multicolumn{1}{c}{ Values } \\
\hline $\mathrm{SST}(\mathrm{K})$ & $288,290,292$ \\
$q_{\mathrm{ft}}\left(\mathrm{g} \mathrm{kg}^{-1}\right)$ & $1.1,3.1,6.1$ \\
$D\left(10^{-6} \mathrm{~s}^{-1}\right)$ & $3.0,5.5,8.0$ \\
\hline
\end{tabular}

to water loss, whereas the semi-polluted and polluted conditions continue to thicken. The dominant physical/dynamical mechanisms due to aerosol perturbations differ for moderate/heavy drizzling and non/light drizzling MSc.

Considering different environmental conditions, the simulated short-time cloud responses are generally consistent with previous studies. For both clean and polluted conditions, under higher SST, drier free-troposphere, or stronger large scale divergence rate, the clouds become thinner than in the corresponding Control case, and surface precipitation decreases in clean conditions. Higher SST causes both cloud top and base heights to increase, with cloud base being lifted more, resulting in a thinner cloud. Lower free-tropospheric humidity leads to stronger evaporationentrainment, and therefore higher TKE and deeper MBL. Also, the mixing of dry air entrained at cloud top with the cloudy air leads to drying of the MBL, causing the cloud base to be higher. Overall, the cloud base elevates more than does the cloud top, thus creating a thinner cloud. Under stronger large scale subsidence, the cloud top is prohibited from rising; consequently the lower cloud top makes the cloud thinner. Under stronger wind speed, the enhanced surface fluxes moisten the MBL, thicken the cloud, and increase precipitation.

An analytical formulation of total cloud susceptibility to aerosol perturbations can be expressed by the sum of the Twomey, droplet dispersion, cloud thickness, and adiabaticity effects. Control, SST290, QFT3, and DIV3 cases covering $N_{\mathrm{a}}$ values of $100,200,500$, and $1000 \mathrm{~cm}^{-3}$ are utilized to evaluate each effect for both nighttime and daytime conditions. The estimated Twomey effect is the dominant term in the total cloud susceptibility and is larger under moister ambient conditions. The sign of the droplet dispersion effect is positive; it is larger for heavier drizzling cases (Control and DIV3), and smaller for non/light drizzling cases (SST290 and QFT3). The dispersion effect plays a minor role in the total cloud susceptibility, accounting for 3-10\% at night. The cloud thickness effect is negative in all cases, expect in DIV3 case, where stronger precipitation occurs in clean case, and thus an increase in $N_{\mathrm{a}}$ suppresses precipitation, causing the cloud to thicken. For non/light drizzling cases (SST290 and QFT3), the magnitude of $\Delta(\ln H) / \Delta\left(\ln N_{\mathrm{a}}\right)$ are smaller; the same trend as in the other effects. The cloud thickness effect is the only one that can reduce the total cloud susceptibility through cloud thinning. 
The estimated magnitude of the total cloud susceptibility, $\Delta(\ln \tau) / \Delta\left(\ln N_{\mathrm{a}}\right)$, is between 0.28 and 0.53 at nighttime, with larger magnitude for heavier drizzling cases and smaller magnitude for non/light drizzling cases. Thus $\Delta(\ln \tau) / \Delta\left(\ln N_{\mathrm{a}}\right)$ is more pronounced under a moister environment with stronger precipitation. Also, the total cloud susceptibility is larger in a cleaner background. Comparing the total cloud susceptibility derived directly from LES results and that calculated based on each individual effect in analytical formulation, there is good agreement, with the difference being within the error bar (Fig. 13). This indicates that the analytical expression is a useful form to evaluate the total cloud susceptibility with reasonable accuracy. In daytime, the range of magnitude of each effect is more scattered as compared to nighttime. Because the MBL decouples and the cloud thins during the day, the evaluation which is based on only cloudy grids has a larger standard deviation should be viewed with more caution. Overall, however, the magnitude of each term during the daytime is larger for moderate/heavy drizzling conditions, consistent with the nighttime tendency.

The ratio of the cloud thickness effect to the Twomey effect $\left(R_{\mathrm{IE}}\right)$ is examined. It is found in a short time scale, the ratio depends on cloud base height and cloud thickness in the unperturbed clouds. For thicker clouds with stronger precipitation and lower cloud base, the cloud thickness effect enhances the Twomey effect. On the other hand, for drier cases with less precipitation and higher cloud base, they tend to have negative $R_{\mathrm{IE}}$, showing that the cloud thickness effect diminishes the Twomey effect. In the simulated cases, $R_{\mathrm{IE}}$ is negative for most cases, showing that when there is non/light precipitation, the cloud thickness effect counteracts the Twomey effect.

From the comprehensive and systematic evaluation of the impact of aerosol, precipitation and meteorological conditions on the evolution of MSc, it is shown that MSc is sensitive to aerosol perturbation under clean background, and to the important meteorological conditions considered. Also, the total cloud susceptibility to aerosol perturbation is larger under heavier drizzling clouds and cleaner environment. Among the Twomey, droplet dispersion, and cloud thickness effects which contribute to the total cloud susceptibility, Twomey effect dominates, droplet dispersion effect plays a minor role, and cloud thickness effect acts to enhance or counteract the Twomey effect, depending on precipitation strength and cloud base height. Moreover, the good agreement of total cloud susceptibility between analytical expression and LES simulation suggests that the analytical formulation is effective in representing the complex aerosolcloud-precipitation interactions and is useful in quantifying the cloud responses to aerosol perturbations.

Acknowledgements. This work was supported by office of Naval Research grant N00014-10-1-0200. The authors thank Frank Li, Adrian Hill, and Andreas Zuend for helpful suggestions. LX acknowledges the support of the Advanced Study Program at NCAR. HW thanks the Fund for Innovative Climate and Energy Research (FICER) at the University of Calgary. Computations were carried out on the CITerra Dell Cluster of the Geological and Planetary Sciences Division at Caltech.

Edited by: B. Stevens

\section{References}

Ackerman, A. S., Toon, O. B., Taylor, J. P., Johnson, D. W., Hobbs, P. V., and Ferek, R. J.: Effects of aerosols on cloud albedo: Evaluation of Twomey's parameterization of the cloud susceptibility using measurement of ship tracks, J. Atmos. Sci., 57, 2684-2695, 2000 .

Ackerman, A. S., Kirkpatrick, M. P., Stevens, D. E., and Toon, O. B.: The impact of humidity above stratiform clouds on indirect aerosol climate forcing, Nature, 432, 1014-1017, 2004.

Ackerman, A. S., vanZanten, M. C., Stevens, B., Savic-Jovcic, V., Bretherton, C. S., Chlond, A., Golaz, J.-C., Jiang, H., Khairoutdinov, M., Krueger, S. K., Lewellen, D. C., Lock, A., Moeng, C.-H., Nakamura, K., Petters, M. D., Snider, J. R., Weinbrecht, S., and Zulauf, M.: Large-eddy simulations of a drizzling, stratocumulus-topped marine boundary layer, Mon. Weather Rev., 137, 1083-1110, doi:10.1175/2008MWR2582.1, 2009.

Albrecht, B.: Aerosols, Cloud Microphysics, and Fractional Cloudiness, Science, 245, 1227-1230, doi:10.1126/science.245.4923.1227, 1989.

Brenguier, J.-L., Pawloska, H., Schüller, L., Preusker, R., and Fischer, J.: Radiative properties of boundary layer clouds: Droplet effective radius versus number concentration, J. Atmos. Sci., 57, 803-821, 2000.

Bretherton, C. S. and Wyant, M. C.: Moisture transport, lower troposphere stability, and decoupling of cloud-topped boundary, J. Atmos. Sci., 54, 148-167, 1997.

Bretherton, C. S., Macvean, M. K., Bechtold, P., Chlond, A., Cotton, W. R., Cuxart, J., Cuijpers, H., Khairoutdinov, M., Kosovic, B., Lewellen, D., Moeng, C.-H., Siebesma, P., Stevens, B., Stevens, D. E., Sykes, I., and Wyant, M. C.: An intercomparison of radiatively driven entrainment and turbulence in a smoke cloud, as simulated by different numerical models, Q. J. Roy. Meteorol. Soc., 125, 391-423, 1999.

Bretherton, C. S., Blossey, P. N., and Uchida, J.: Cloud droplet sedimentation, entrainment efficiency, and subtropical stratocumulus albedo, Geophys. Res. Lett., 34, L03813, doi:10.1029/2006GL027648, 2007.

Caldwell, P. and Bretherton, C. S.: Response of a subtropical stratocumulus-capped mixed layer to climate and aerosol changes, J. Climate, 22, 20-38, 2009a.

Caldwell, P. and Bretherton, C. S.: Large eddy simulation of the diurnal cycle in Southeast Pacific stratocumulus, J. Atmos. Sci., 66, 432-449, 2009b.

Chlond, A. and Wolkau, A.: Large-eddy simulation of a nocturnal stratocumulus-topped marine atmospheric boundary layer: An uncertainty analysis, Bound-Lay. Meteorol., 95, 31-55, 2000.

Deardorff, J.: Stratocumulus-capped mixed layers derived from a three dimensional model, Bound-Lay. Meteorol., 18, 495-527, 
1980.

Duynkerke, P. G., de Roode, S. R., van Zanten, M. C., Calvo, J., Cuxart, J., Cheinet, S., Chlond, A., Grenier, H., Jonker, P. J., Kohler, M., Lenderink, G., Lewellen, D., Lappen, C.-L., Lock, A. P., Moeng, C.-H., Muller, F., Olmeda, D., Piriou, J.-M., Sanchez, E., and Sednev, I.: Observations and numerical simulations of the diurnal cycle of the EUROCS stratocumulus case, Q. J. Roy. Meteor. Soc., 604, 3269-3296, 2004.

Feingold, G. and Chuang, P. Y.: Analysis of the influence of filmforming compounds on droplet growth: Implications for cloud microphysical processes and climate, J. Atmos. Sci., 59, 20062018, 2002.

Feingold, G., Tzivion, S., and Levin, Z.: Evolution of raindrop spectra. Part I: solution to the stochastic collection/breakup equation using the method of moments, J. Atmos. Sci., 45, 3387-3399, 1988.

Feingold, G. and Seibert, H.: Cloud-Aerosol Interactions from the micro to cloud scale, in: Clouds in the perturbed climate system: their relationship to energy balance, atmospheric dynamics, and precipitation, edited by: Heintzenberg, J. and Charlson, R. J., 319-338, MIT Press, Cambridge, UK, 2009.

Geresdi, I.: Idealized simulation of the Colorado hailstorm case: comparison of bulk and detailed microphysics, Atmos. Res., 45, 237-252, 1998.

Hall, W. D.: A detailed microphysical model within a twodimensional framework: Model description and preliminary results, J. Atmos. Sci., 37, 2486-2507, 1980.

Hill, A. A., Dobbie, S., and Yin, Y.: The impact of aerosols on non-precipitating marine stratocumulus., Q. J. Roy. Meteor. Soc., 134, 1143-1154, doi:10.1002/qj.278, 2008.

Hill, A. A., Feingold, G., and Jiang, H.: The influence of entrainment and mixing assumption on aerosol-cloud interactions in marine stratocumulus, J. Atmos. Sci., 66, 1450-1464, 2009.

IPCC: Summary for Policymakers, in: Climate Change 2007: The Physical Science Basis. Contribution of Working Group I to the Fourth Assessment Report of the Intergovernmental Panel on Climate Change, edited by: Solomon, S., Qin, D., Manning, M., Chen, Z., Marquis, M., Averyt, K. B., Tignor, M., and Miller, H. L., Cambridge University Press, UK, 2007.

Jiang, H., Feingold, G., and Cotton, W. R.: Simulations of aerosolclouddynamical feedbacks resulting from entrainment of aerosol into the marine boundary layer during the Atlantic Stratocumulus Transition Experiment, J. Geophys. Res., 107, 4813, doi:10.1029/2001JD001502, 2002.

Klein, S. A. and Hartmann, D. L.: The seasonal cycle of low stratiform clouds, J. Climate, 6, 1588-1606, 1993.

Lewellen, D. C. and Lewellen, W. S.: Entrainment and decoupling relations for cloudy boundary layers, J. Atmos. Sci., 59, 2966-2986, doi:10.1175/15200469(2002)059;2966:EADRFC ¿2.0.CO;2, 2002.

Lilly, D. K.: Models of cloud topped mixed layers under a strong inversion, Q. J. Roy. Meteor. Soc., 94, 292-309, 1968.

Lilly, D. K.: Entrainment into mixed layers. Part II: A new closure, J. Atmos. Sci., 59, 3353-3361, 2002.

Liu, Y. G. and Daum, P. H.: Anthropogenic aerosols: Indirect warming effect from dispersion forcing, Nature, 419, 580-581, 2002.

Lu, M. and Seinfeld, J. H.: Study of the aerosol indirect effect by large-eddy simulation of marine stratocumulus, J. Atmos. Sci.,
62, 3909-3932, 2005.

Lu, M. and Seinfeld, J. H.: Effect of aerosol number concentration on cloud droplet dispersion: A large-eddy simulation study and implications for aerosol indirect forcing, J. Geophys. Res., 111, D02207, doi:10.1029/2005JD006419, 2006.

Lu, M.-L., Conant, W. C., Jonsson, H. H., Varutbangkul, V., Flagan, R. C., and Seinfeld, J. H.: The Marine Stratus/Stratocumulus Experiment (MASE): Aerosol-cloud relationships in marine stratocumulus, J. Geophys. Res., 112, D10209, doi:10.1029/2006JD007985, 2007.

Martin, G. M., Johnson, D. W., and Spice, A.: The measurement and parameterization of effective radius of droplets in warm stratocumulus clouds, J. Atmos. Sci., 51, 1823-1842, 1994.

Miles, N. L., Verlinde, J., and Clothiaux, E. E.: Cloud droplet size distributions in low-level stratiform clouds, J. Atmos. Sci., 57, 295-311, 2000.

Mlawer, E. J., Taubman, S. J., Brown, P. D., Iacono, M. J., and Clough, S. A.: Radiative transfer for inhomogeneous atmospheres: RRTM, a validated correlated-k model for the longwave, J. Geophys. Res., 102, 16663-16682, 1997.

Moeng, C.-H., Dudhia, J., Klemp, J. B., and Sullivan, P. P.: Examining two-way grid nesting for large eddy simulation of the PBL using the WRF model, Mon. Weather Rev., 135, 2295-2311, doi:10.1175/MWR3406.1, 2007.

Nicholls, S: The dynamics of stratocumulus - aircraft observations and comparisons with a mixed layer model, Q. J. Roy. Meteor. Soc., 110, 783-820, doi:10.1256/smsqj.46601, 1984.

Petters, M. D. and Kreidenweis, S. M.: A single parameter representation of hygroscopic growth and cloud condensation nucleus activity, Atmos. Chem. Phys., 7, 1961-1971, doi:10.5194/acp-71961-2007, 2007.

Pincus, R. and Baker, M. B.: Effect of precipitation on the albedo susceptibility of marine boundary layer clouds, Nature, 372, 250-252, 1994.

Pruppacher, H. R. and Klett, J. D.: Microphysics of Clouds and Precipitation, Kluwer Academic Publishers, Boston, 1997.

Randall, D. A.: Stratocumulus cloud deepening through entrainment, Tellus, 36, 446-457, 1984.

Randall, D. A., Coakley Jr., J. A., Fairall, C. W., Kropfli, R. A., and Lenschow, D. H.: Outlook for research on subtropical marine stratiform clouds, B. Am. Meteorol. Soc., 65, 1290-1301, 1984.

Rasmussen, R. M., Geresdi, I., Thompson, G., Manning, K., and Karplus, E.: Freezing drizzle formation in stably stratified layer clouds: The role of radiative cooling of cloud droplets, cloud condensation nuclei, and ice initiation, J. Atmos. Sci., 59, 837860, 2002.

Reisin, T., Levin, Z., and Tzivion, S.: Rain production in convective clouds as simulated in an axisymmetric model with detailed microphysics. Part I: description of the model, J. Atmos. Sci., 53, 497-519, 1996.

Rotstayn, L. D. and Liu, Y.: Sensitivity of the first indirect aerosol effect to an increase of cloud droplet spectral dispersion with droplet number concentration, J. Climate, 16, 3476- 3481, 2003.

Rotstayn, L. D. and Liu, Y.: Cloud droplet spectral dispersion and the indirect aerosol effect: Comparison of two treatments in a GCM, Geophys. Res. Lett., 36, doi:10.1029/2009GL038216, 2009.

Sandu, I., Brenguier, J., Geoffroy, O., Thouron, O., and Masson, V.: Aerosol impacts on the diurnal cycle of marine stratocumulus, J. 
Atmos. Sci., 65, 2705-2718, 2008.

Sandu, I., Brenguier, J.-L., Thouron, O., and Stevens, B.: How important is the vertical structure for the representation of aerosol impacts on the diurnal cycle of marine stratocumulus?, Atmos. Chem. Phys., 9, 4039-4052, doi:10.5194/acp-9-4039-2009, 2009.

Savic-Jovcic, V. and Stevens, B.: The structure and mesoscale organization of precipitating stratocumulus, J. Atmos. Sci., 65, 15871605, 2008.

Seinfeld, J. H. and Pandis, S. N.: Atmospheric Chemistry and Physics, John Wiley and Sons, Inc., Hoboken, NJ, 2 edn., 2006.

Shao, H. and Liu, G.: A critical examination of the observed first aerosol indirect effect, J. Atmos. Sci., 66, 1018-1032, 2009.

Stevens, B.: Cloud transitions and decoupling in shear-free stratocumulus-topped boundary layers, Geophys. Res. Lett., 27, 2557-2560,doi:10.1029/1999GL011257, 2000.

Stevens, B.: Atmospheric moist convection, Annu. Rev. Earth Pl. Sc., 33, 605-643, doi:10.1146/annurev.earth.33.092203.122658, 2005.

Stevens, B.: Bulk boundary-layer concepts for simplified models of tropical dynamics, Theor. Comp. Fluid Dyn., 20, 279-304, doi:10.1007/s00162-006-0032-z, 2006.

Stevens, B. and Brenguier, J.-L.: Cloud controlling factors: low clouds, in: Clouds in the perturbed climate system: their relationship to energy balance, atmospheric dynamics, and precipitation, edited by: Heintzenberg, J. and Charlson, R. J., 173-196, MIT Press, 2009.

Stevens, D. E. and Bretherton, C. S.: Effects of resolution on the simulation of stratocumulus entrainment, Q. J. Roy. Meteor. Soc., 125, 425-439, 1999.

Stevens, B. and Feingold, G.: Untangling aerosol effects on clouds and precipitation in a buffered system, Nature, 461, 607-613, doi:10.1038/nature08281, 2009.

Stevens, B., Cotton, W. R., Feingold, G., and Moeng, C.H.: Large-eddy simulations of strongly precipitating, shallow, stratocumulus-topped boundary layers, J. Atmos. Sci., 55, 36163638, 1998.

Stevens, B., Lenschow, D. H., Faloona, I., Moeng, C.-H., Lilly, D. K., Blomquist, B., Vali, G., Bandy, A., Campos, T., Gerber, H., Haimov, S., Morley, B., and Thornton, D.: On entrainment rates in nocturnal marine stratocumulus, Q. J. Roy. Meteor. Soc., 129, 3469-3493, doi:10.1256/qj.02.202, 2003.

Stevens, B., Moeng, C.-H., Ackerman, A. S., Bretherton, C. S., Chlond, A., De Roode, S., Edwards, J., Golaz, J., Jiang, H., Khairoutdinov, M., Kirkpatrick, M. P., Lewellen, D. C., Lock, A., Muller, F., Stevens, D. E., Whelan, E., and Zhu, P.: Evaluation of large-eddy simulations via observations of nocturnal marine stratocumulus, Mon. Weather Rev., 133, 1443-1462, 2005.

Turton, J. and Nicholls, S.: A study of the diurnal variation of stratocumulus using a multiple mixed-layer model, Q. J. Roy. Meteor. Soc., 113, 969-1011, 1987.

Twomey, S.: The nuclei of natural cloud formation Part 2: The supersaturation in natural clouds and the variation of cloud droplet concentration, Pure Appl. Geophys., 43, 243-249, 1959.

Twomey, S.: The influence of pollution on the shortwave albedo of clouds, J. Atmos. Sci., 34, 1149-1152, 1977.
Tzivion, S., Feingold, G., and Levin, Z.: An efficient numerical solution to the stochastic collection equation, J. Atmos. Sci., 44, 3139-3149, 1987.

Tzivion, S., Feingold, G., and Levin, Z.: The evolution of raindrop spectra. Part II: collisional collection/breakup and evaporation in a rainshaft, J. Atmos. Sci., 46, 3312-3327, 1989.

Uchida, J., Bretherton, C. S., and Blossey, P. N.: The sensitivity of stratocumulus-capped mixed layers to cloud droplet concentration: do LES and mixed-layer models agree?, Atmos. Chem. Phys., 10, 4097-4109, doi:10.5194/acp-10-4097-2010, 2010.

Wang, H. and Feingold, G.: Modeling mesoscale cellular structures and drizzle in marine stratocumulus. Part I: Impact of drizzle on the formation and evolution of open cells, J. Atmos. Sci., 66, 3237-3256, 2009a.

Wang, H. and Feingold, G.: Modeling mesoscale cellular structures and drizzle in marine stratocumulus. Part II: The microphysics and dynamics of the boundary region between open and closed cells, J. Atmos. Sci., 66, 3257-3275, 2009b.

Wang, S., Wang, Q., and Feingold, G.: Turbulence, condensation, and liquid water transport in numerically simulated nonprecipitating stratocumulus clouds, J. Atmos. Sci., 60, 262-278, 2003.

Wang, H., Skamarock, W. C., and Feingold, G.: Evaluation of scalar advection schemes in the advanced research WRF model using large-eddy simulations of aerosol-cloud interactions, Mon. Weather Rev., 137, 2547-2558, doi:10.1175/2009MWR2820.1, 2009.

Wang, H., Feingold, G., Wood, R., and Kazil, J.: Modeling microphysical and meteorological controls on precipitation and cloud cellular structures in Southeast Pacific stratocumulus, Atmos. Chem. Phys., 10, 6347-6362, doi:10.5194/acp-10-6347-2010, 2010.

Warren, S. G., Hahn, C. J., London, J., Chervine, R. M., , and Jenne, R. L.: Global distribution of total cloud cover and cloud type amounts over the ocean, NCAR/TN-317 STR, NCAR Tech. Note., 41 pp., 1988.

Wood, R.: Cancellation of aerosol indirect effects in marine stratocumulus through cloud thinning, J. Atmos. Sci., 64, 26572669, doi:10.1175/JAS3942.1, 2007.

Wood, R., Irons, S., and Jonas, P. R.: How important is the spectral ripening effect in stratiform boundary layer clouds? Studies using simple trajectory analysis, J. Atmos. Sci., 59, 2681-2693, 2002.

Xue, H. and Feingold, G.: Large-eddy simulations of trade wind cumuli: Investigation of aerosol indirect effects, J. Atmos. Sci., 63, 1605-1622, 2006.

Xue, L., Teller, A., Rasmussen, R. M., Geresdi, I., and Pan, Z.: Effects of aerosol solubility and regeneration on warmphase orographic clouds and precipitation simulated by a detailed bin microphysical scheme, J. Atmos. Sci., 67, 3336-3354, doi:10.1175/2010JAS3511.1, 2010.

Yamaguchi, T. and Randall, D. A.: Large-eddy simulation of evaporatively driven entrainment in cloud-topped mixed layers, J. Atmos. Sci., 65, 1481-1504, 2008. 